\title{
Laminin/ $\beta 1$ integrin signal triggers axon formation by promoting microtubule assembly and stabilization
}

\author{
Wen-Liang Lei ${ }^{1}$, Shi-Ge Xing ${ }^{2}$, Cai-Yun Deng ${ }^{1}$, Xiang-Chun $\mathrm{Ju}^{1}$, Xing-Yu Jiang ${ }^{2}$, Zhen-Ge Luo ${ }^{1}$ \\ ${ }^{1}$ Institute of Neuroscience and Key State Laboratory of Neuroscience, Chinese Academy of Sciences, Shanghai 200031, China; \\ ${ }^{2}$ National Center for NanoScience and Technology of China, Beijing 100190, China
}

\begin{abstract}
Axon specification during neuronal polarization is closely associated with increased microtubule stabilization in one of the neurites of unpolarized neuron, but how this increased microtubule stability is achieved is unclear. Here, we show that extracellular matrix (ECM) component laminin promotes neuronal polarization via regulating directional microtubule assembly through $\beta 1$ integrin (Itgb1). Contact with laminin coated on culture substrate or polystyrene beads was sufficient for axon specification of undifferentiated neurites in cultured hippocampal neurons and cortical slices. Active Itgb1 was found to be concentrated in laminin-contacting neurites. Axon formation was promoted and abolished by enhancing and attenuating Itgb1 signaling, respectively. Interestingly, laminin contact promoted plus-end microtubule assembly in a manner that required Itgb1. Moreover, stabilizing microtubules partially prevented polarization defects caused by Itgb1 downregulation. Finally, genetic ablation of Itgb1 in dorsal telencephalic progenitors caused deficits in axon development of cortical pyramidal neurons. Thus, laminin/Itgb1 signaling plays an instructive role in axon initiation and growth, both in vitro and in vivo, through the regulation of microtubule assembly. This study has established a linkage between an extrinsic factor and intrinsic cytoskeletal dynamics during neuronal polarization.
\end{abstract}

Keywords: laminin; integrin; axon formation; microtubule assembly

Cell Research (2012) 22:954-972. doi:10.1038/cr.2012.40; published online 20 March 2012

\section{Introduction}

A typical neuron is comprised of a long axon and several short and highly arborized dendrites. This polarized structure is required for unidirectional information flow. It is generally believed that axon development requires cytoskeleton reorganization mediated by a number of signaling pathways [1-3]. Actin dynamics at the growth cone is required for the axon growth $[4,5]$. It has been shown recently that microtubule stabilization induced by pharmacological treatments is sufficient to induce the axon formation $[3,6]$, and markedly increases axon regeneration after injury [7]. Many cytoplasmic signaling molecules are involved in neuronal polarization and axon development $[1,2,8]$, most of which have been identified in cultured hippocampal or cortical neurons, widely

\footnotetext{
Correspondence: Zhen-Ge Luo

E-mail: zgluo@ion.ac.cn

Received 9 February 2012; revised 15 February 2012; accepted 17 February 2012; published online 20 March 2012
}

used model systems for the study of neuronal polarity [911]. Among them, several kinases, including SAD A/B and LKB1, are essential for neuronal polarization in vivo $[8,12-14]$. In contrast, the identity of the extracellular factors that initiate neuronal polarity in vivo is just beginning to be elucidated $[15,16]$. Furthermore, the linkage between extracellular cues and intracellular mediators remains largely unclear.

Cultured hippocampal neurons tend to form axons preferentially on the substrates coated with extracellular matrix (ECM) component laminin or neuron-glia cell adhesion molecule $(\mathrm{NgCAM} / \mathrm{L} 1)$ than on poly-L-lysine $[17,18]$, suggesting that ECM or cell surface components may serve as extrinsic cues for neuronal polarization. A recent report shows that laminin contact correlates with the emergence of oriented axon of retinal ganglion cells in the zebrafish larvae [16]. Isoforms of laminin are expressed in the developing rodent brain, some of which may be present in ventricular and subventricular zone where cortical neurons become polarized [19]. Among laminin receptors, integrin family of heterodimeric cell 
adhesion molecules are involved in initial neuritogenesis [20], neurite outgrowth and regeneration [21], axon path finding [22], neuronal positioning [23-25], as well as synaptic development and plasticity [26]. However, whether and how integrin-mediated cell adhesion is involved in neuronal polarization is unknown.

In this work, we have demonstrated that laminin/ integrin interaction is indispensable for neuronal polarization both in vitro and in vivo. Laminin contact causes polarized activation of Itgb1 as well as axon initiation in isolated hippocampal neurons. Furthermore, laminininduced axon initiation required Itgb1, and activation of Itgb1 directly by antibody cross-linking was sufficient to induce axon initiation. Interestingly, we found that laminin-contacting neurites of unpolarized neurons exhibited enhanced microtubule stability, which is known to enable axon initiation, and this microtubule stabilization required Itgb1. In support of the notion that Itgb1dependent microtubule stabilization is critical for axon initiation, stabilizing microtubules by the taxol treatment compensated the deficit of axon formation due to Itgbl downregulation. Notably, loss of Itgb1 resulted in a decrease in the level of phosphorylated LKB1 and SAD kinases, which are known to be critical for axon initiation in vivo. Thus, $\mathrm{ECM} /$ integrin signaling acts via intrinsic pathways to promote directional microtubule assembly and axon development.

\section{Results}

Figure 1 Itgb1 is required for laminin-induced axon initiation. (A) HEK293 cells or cultured rat cortical neurons were transfected with pSUPER vector or pSUPER encoding siRNAs against Itgb1 (\#1, 2, 3, or 4) or scrambled sequence. Protein levels of Itgb1 were analyzed by immunoblotting (IB), with $\beta$-actin as loading control. Note that \#2 and 3 were effective in downregulating Itgb1 in rat primary neurons and HEK293 cells, whereas \# 4 had no effect on Itgb1 in HEK293 cells. Thus, human Itgb1 (h-Itgb1) was used for the following rescue experiment. (B) Dissociated hippocampal neurons were transfected with pSUPER vector or pSUPER encoding Itgb1 siRNA or scrambled sequence or Itgb1 siRNA plus human Itgb1 expression construct. Transfected neurons were marked by EGFP and stained with axonal marker Smi-312. Cells were cultured on laminin substrate. Scale bar, $20 \mu \mathrm{m}$. (C) Quantification for neuronal polarity. Transfected neurons were classified into three categories: neurons with short neurites in similar length but without axon (NA), neurons with one process that was positive for Smi-312, and over $100 \mu \mathrm{m}$ and at least twice as long as the second longest process (SA), and neurons with two or more processes positive for Smi-312 and $>100 \mu \mathrm{m}$ and twice as long as other neurites (MA). Data are presented as mean \pm SEM of 300 neurons from six experiments. ${ }^{* *} P<0.01$. (D, E) Hippocampal neurons at DIV1 were treated with Itgb1-linking antibody 9EG7 or vehicle control for $48 \mathrm{~h}$. Neuronal polarity (D) and axonal length (E) were quantitatively analyzed. Data are shown as mean \pm SEM of 150 neurons from three experiments. Axonal length of control group was normalized as $1.0 .{ }^{* *} P<0.01,{ }^{* * *} P<0.001$. (F) Hippocampal neurons transfected with EGFP were cultured on substrates coated with laminin stripes. After $12 \mathrm{~h}$, cultures were stained with HUTS4 antibody to label active Itgb1. Laminin stripes were marked by Alexa647-conjugated BSA signals. (G) HUTS4 intensity against EGFP was quantified in the on-stripe and off-stripe neurites with average value of off-stripe normalized as 1. ${ }^{*} P<0.05$. (H) Hippocampal neurons were transfected with pSUPER constructs encoding Itgb1 siRNA or scrambled sequence (Ctrl), and cultured on substrates coated with laminin stripes (blue) and PDL. After $48 \mathrm{~h}$, cultures were stained with Smi-312 antibody. The laminin stripes were visualized by BSA-Alexa647 mixed in the laminin solution during coating. Scale bar, $20 \mu \mathrm{m}$. (I) Preference index (PI, defined as [(\% on stripe) $-(\%$ off stripe $)] / 100 \%)$ was analyzed to reflect the preference of axon initiation sites to different substrates for neurons without or with Itgb1 downregulation (see Supplementary information, Figure S4 for details of the analysis).

www.cell-research.com | Cell Research 
A

B
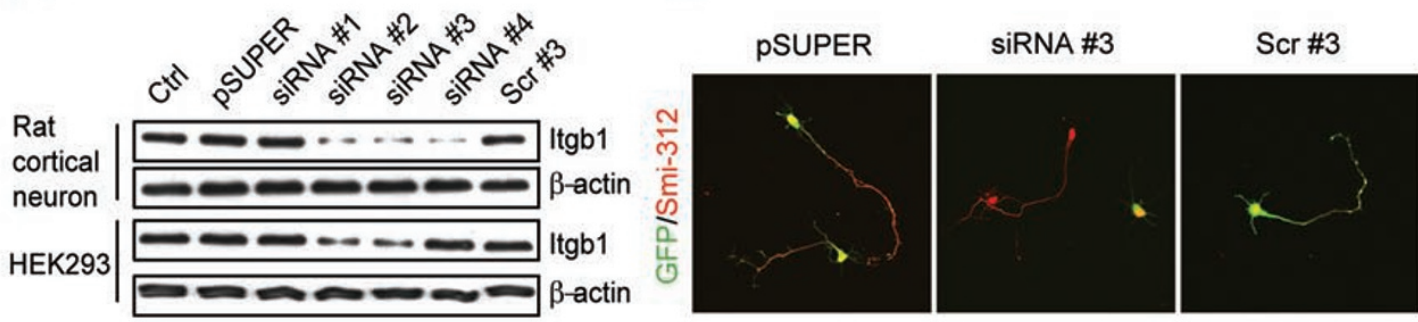

siRNA \#4 $+\mathrm{h}-\operatorname{ltgb} 1$

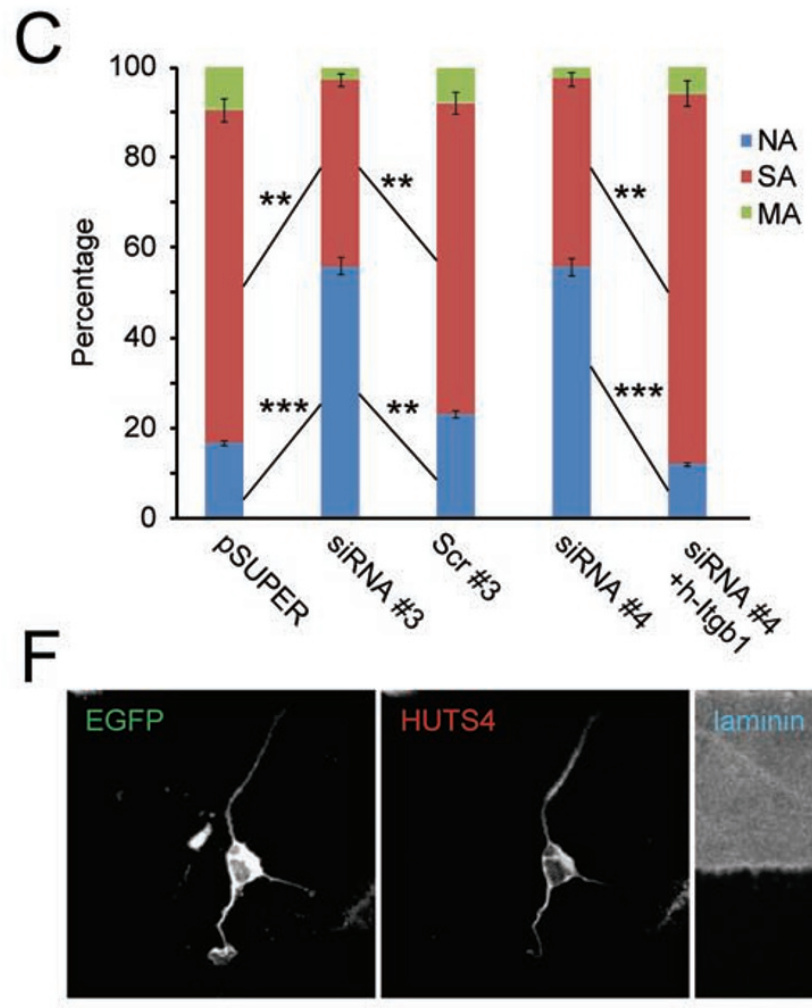

D
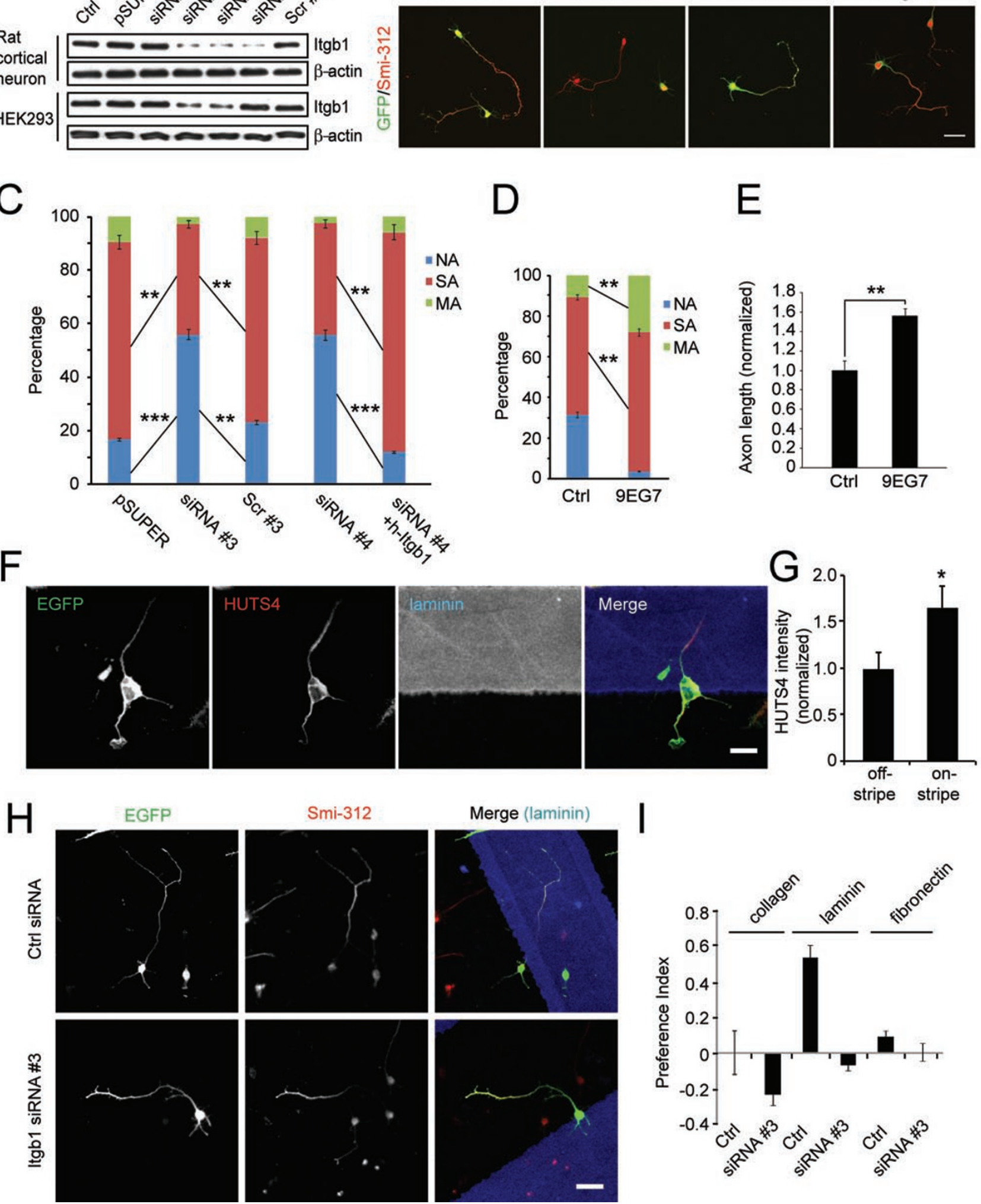
determined by treating hippocampal neurons with Itgb1 function-blocking antibody, P5D2 or HM $\beta 1-1$ [28-30]. We found that blocking Itgb1 activity decreased SA neurons and increased NA neurons (Supplementary information, Figure S2). Thus, Itgb1 signaling is required for axon formation in these cultured neurons. Next, we treated cultured hippocampal neurons with 9EG7 antibody to induce the cross-linking and activation of Itgb1 [31]. In contrast to blocking antibodies, 9EG7 treatment led to an increase in the percentage of neurons bearing either SA or multiple axons (MA) (Figure 1D) and in the average axon length (Figure 1E). We also analyzed whether modulating Itgb1 signals had any effect on other neurites, which are destined to become dendrites. Interestingly, the above treatments had no effect on either total neurite number or length of minor neurites (Supplementary information, Figure S3). Thus, Itgb1 activation is both necessary for axon development on laminin substrate and by itself is sufficient to increase axon formation.

Previous studies have shown that neurites of cultured hippocampal neurons tend to differentiate into axons when contacting laminin stripes or facing an increasing laminin gradient coated on the substrate $[17,18]$. We found that in most cases, the on-stripe neurites of unpolarized neurons exhibited higher immunostaining for active Itgb1 (Figure 1F and 1G). In agreement with the previous report [18], the majority of axon tips of polarized neurons in 48 -h cultures were located on the laminin stripes (Figure $1 \mathrm{H}$ and Supplementary information, Figure S4B). To distinguish the effect of laminin stripe on axon differentiation from that on the guidance of axon growth, we analyzed the initiation site of axons for all neurons with the soma located at the stripe boundary (see Supplementary information, Figure S4A for the analysis method). Since the location of the initiation site remained unchanged during the $48 \mathrm{~h}$ in culture, this analysis allows us to determine retrospectively the effect of the stripe on the axon differentiation of the neurite [14]. Notably, more axon differentiation was observed for neurites on the laminin stripe than off the stripe, whereas this preference for axon differentiation was not found for stripes coated with collagen or fibronectin, two other ECM components expressed in the pia surface but not within CNS [19] (Figure 1H and 1I; Supplementary information, Figures S4B and S5B). Furthermore, the effect of laminin stripes on axon differentiation was absent in neurons that expressed \#3 siRNA against Itgb1 (Figure $1 \mathrm{H}$ and 1I; Supplementary information, Figure S4B) or treated with Itgb1 function-blocking antibodies (Supplementary information, Figure S5). The effects of substrate stripes on axon initiation site from the soma were quantified by the preference index (Figure 1I and Supplementary information, Figure S5B).

\section{Patterned laminin and Itgb1 are necessary for oriented} axon formation in cultured cortical slices

The existence of extracellular cues for neuronal polarization and axon/dendrite growth in vivo was shown by a slice overlay assay, in which fluorescently labeled dissociated cortical neurons plated onto the cortical slices exhibit the tendency of axon growth towards ventricular zone (VZ) [32]. Given the high level of Itgb1 and laminin in the ventricular and subventricular regions [19], we have examined whether laminin is important for directional axon growth in this assay. Dissociated cortical neurons were transfected with GFP and plated onto cortical slices from P0 rats and cultured for $48 \mathrm{~h}$. We found that the majority of cells $(\sim 75 \%)$ extended an axon that was oriented radially toward the VZ, as reflected by the angular distribution of both the initiation site on the soma and the location of axon tips relative to the center of the soma at $48 \mathrm{~h}$ (with 0 to $+90^{\circ}$ defined as ventricular direction and 0 to $-90^{\circ}$ as pia direction) (Figure 2A, 2C and 2D). This radially oriented axon growth is consistent with the previous report [32]. However, when cortical slices were pre-incubated with a high concentration of exogenous laminin, axons of overlaid neurons initiated from the soma at random angles, and their axon tip locations also showed no directional preference (Figure $2 \mathrm{~A}, 2 \mathrm{C}$ and 2D). This interference of axon initiation and growth orientation by exogenous laminin suggests that the endogenous laminin in the cortex may serve as the extrinsic cue for axon formation and growth. Furthermore, similar loss of preferential axon initiation and growth was found for cortical neurons that were transfected with \#3 siRNA against Itgb1 before plating (Figure 2B-2D), indicating that Itgb1 mediates the directional axon initiation and growth in this overlay assay.

Next, we generated a gradient of bound laminin using diffusive printing method $[33,34]$ to mimic the potential cortical distribution of laminin [19]. As shown in Figure $2 \mathrm{E}$, the bound laminin gradient was confirmed by immunostaining with anti-laminin antibody. Dissociated hippocampal neurons were transfected with \#3 siRNA or scrambled siRNA before they were plated onto the bound laminin gradient. After culturing for $48 \mathrm{~h}$, the initiation site of axon on the soma and the location of the axon tip relative to the center of the soma were analyzed to determine the effect of laminin gradient on axon initiation and growth orientation. We found that the majority $(\sim 80 \%)$ of control (scramble siRNA-transfected) neurons showed axon initiation and growth cone orientation towards the 

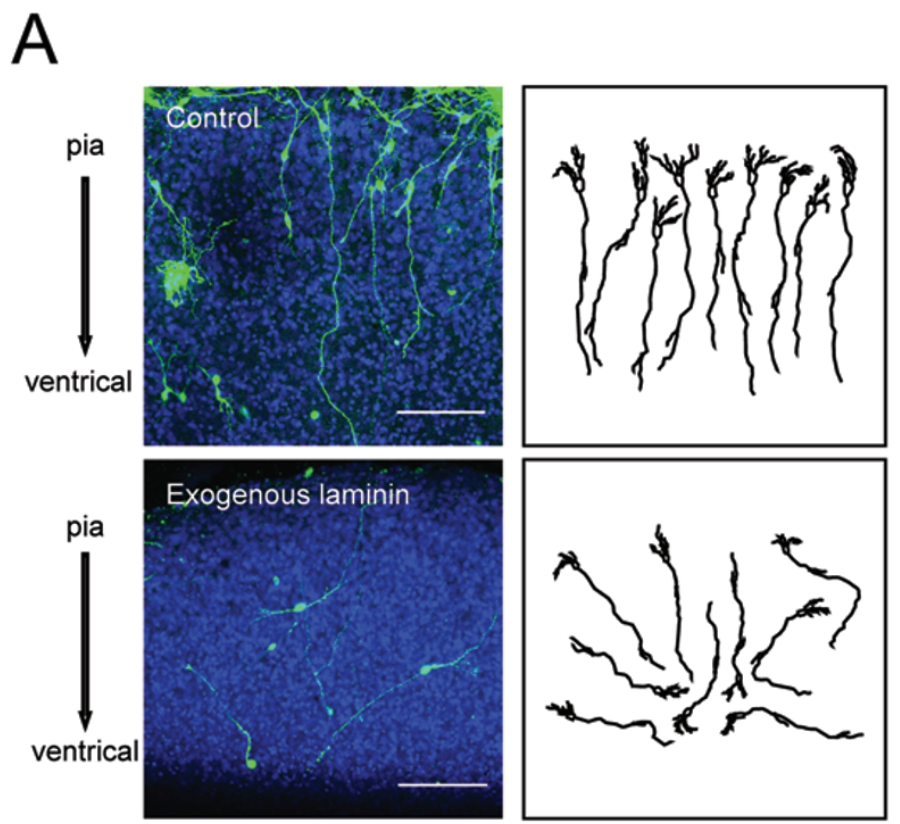

B
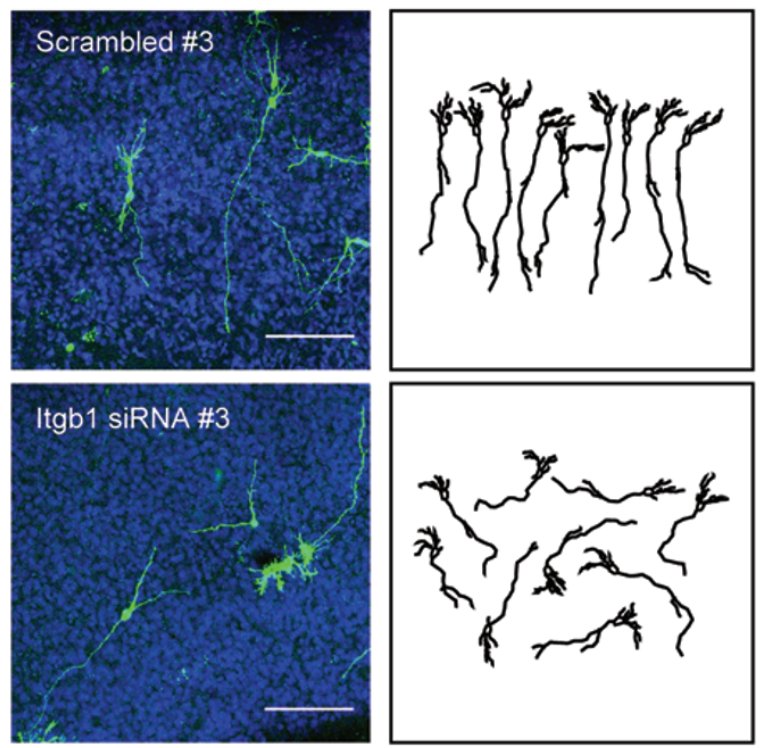

$\mathcal{C}$
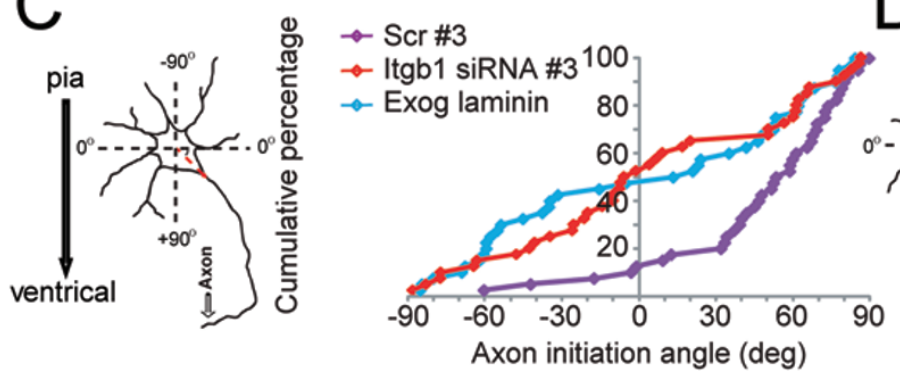

D
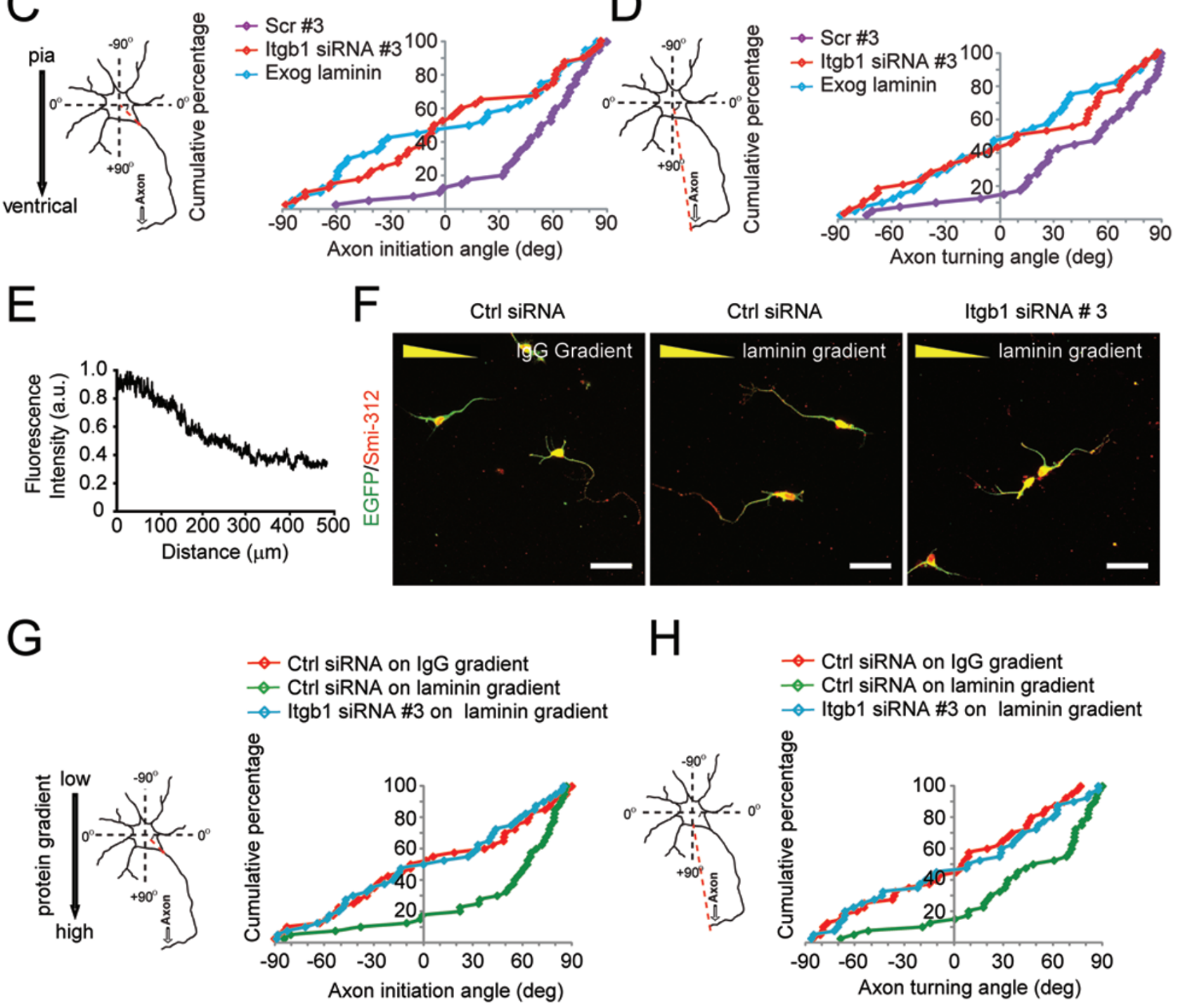

Cell Research | Vol 22 No 6 | June 2012 
Figure 2 Patterned laminin determines directional axon growth in Itgb1-dependent manner. (A-D) Isolated cortical neurons were transfected with pSUPER plasmids (A) or plasmids encoding Itgb1 siRNA or scrambled sequence (B), and plated onto coronal cortical slices from P0 rats. Under some circumstances, slices were pretreated without or with exogenous laminin (100 $\mu \mathrm{g} / \mathrm{ml}$ ) to perturb endogenous laminin patterns (A). After culturing for $48 \mathrm{~h}$, morphology of overlayed neurons was traced (A and $\mathbf{B}$, right panels) and directions of axonal extension were analyzed (C, D). Angles of the axon initiation (C) or turning (D) varied from $+90^{\circ}$ to $-90^{\circ}$, with the positive or negative value, indicating that the axon was initiated or turned toward the ventricle or pia side of the cortical slices, respectively. Data shown are cumulative percentage plots for the distribution of axon initiation angles and axon turning angles for all sampled single-axon neurons (C, D). Data were analyzed using KolmogorovSmirnov test $(P<0.001$, control vs Itgb1 siRNA; $P<0.001$, control vs exogenous laminin; $n=40$ for all experimental groups). Scale bars, $20 \mu \mathrm{m}$. (E) Surface-bound laminin gradient generated by diffusive printing method (see Materials and Methods for details). Laminin gradients were ascertained by immunostaining and fluorescent intensity profile was plotted. (F-H) Isolated hippocampal neurons were transfected with pSUPER plasmids that encodes control scrambled sequence or Itgb1 siRNA, and plated onto either IgG or laminin gradients. After $48 \mathrm{~h}$, neurons were stained with Smi-312 antibody (F). Cumulative percentage of axon initiation and turning angles for all sampled single-axon neurons was plotted (G, H). Angles with positive value $\left(0^{\circ}\right.$ to $\left.90^{\circ}\right)$ or negative value $\left(-90^{\circ}\right.$ to $\left.0^{\circ}\right)$ indicate that the axon was initiated or turned toward the high- and low-density side of the gradient, respectively. Data were analyzed using Kolmogorov-Smirnov test $(P<0.001$, IgG gradients vs laminin gradients; $P<0.001$, Ctrl siRNA on laminin vs Itgb1 siRNA on laminin; $n=40$ for all experimental groups).

side of high-level laminin (Figure 2F-2H). In contrast, no initiation or growth orientation was found when neurons were plated on a gradient of bound IgG or were transfected with \#3 siRNA against Itgb1 (Figure 2F-2H) or were treated with Itgb1 function-blocking antibodies (Supplementary information, Figure S6). Thus, Itgb1 mediates axon initiation and growth orientation on a substrate with bound laminin gradient.

\section{Laminin contact is sufficient to orient axon formation via Itgb1 in cultured cortical slices}

Having determined the essential role of laminin/ Itgb1 signaling in axon initiation and growth in cultured neurons, we next investigated whether laminin contact is sufficient to trigger axon formation within the neural tissue environment and whether the effect requires Itgbl. For this purpose, we applied polystyrene beads pre-coated with laminin or a control protein (IgG) to cultured brain slices prepared at P2 from different types of mice (Itgb ${ }^{f f f}$ or $\left.\operatorname{Itg} b 1^{f / \uparrow}\right)$ electroporated with pCAG-IRES-EGFP either alone (control) or together with Cre-containing plasmid at E15.5. After $48 \mathrm{~h}$, the identity and length of beadcontacting processes were analyzed. Thin and tapered processes emerging from the soma were considered as axon- and dendrite-like, respectively. We found that, in comparison with IgG beads, significantly more laminin beads were found to be associated with axon-like processes in slices from both $\operatorname{Igb} 1^{f f f}$ (control) and $\operatorname{Igb} 1^{f / 4}$ Cre mice (Figure 3A, 3B and 3E). Importantly, laminin bead-contacting processes were much more likely to exhibit axon-like morphology in both $\operatorname{Itgbl} 1^{f f}$ and $\operatorname{Itg} b 1^{f / 4}$. Cre mice (Figure 3A-3C, 3F). Furthermore, this association of laminin beads with axon-like processes was not observed in brain slices from Itgb1 $1^{\text {fff }}$-Cre mice (Figure $3 \mathrm{D}-3 \mathrm{~F})$. These results support the notion that laminin- induced axon formation was impaired when Itgb1 was fully eliminated in the neuron. In addition, processes contacted by laminin-coated beads were significantly longer than those contacted by IgG beads in $\operatorname{Ig} b I^{f f}$ and $\operatorname{Itg} b f^{f /+}$-Cre slices, but not in slices from Itgb1-eliminated $\left(\operatorname{Itg} b 1^{\mathrm{fff}}-\mathrm{Cre}\right.$ ) mice (Figure 3G). Thus, laminin contact is sufficient to promote axon differentiation and growth in the brain tissue in an Itgb1-dependent manner.

\section{Itgb1 regulation of neuronal polarity proteins}

We next investigated the mechanism of Itgb1 action by detecting levels or states of neuronal polarity-associated proteins in Itgb1 $\mathrm{cKO}$ mice (Itgb $1^{\text {fff }}$; Emxl-Cre), which restricted Itgb1 deletion in dorsal telencephalic progenitors [37, 38]. First, we determined the state of integrin-linked kinase (ILK), which has been shown to be involved in axon development of cultured hippocampal neurons [49]. Surprisingly, we found a marked increase in the steady-state level of ILK and phosphorylated AKT (pAKT) at S473, the consensus phosphorylation site by ILK [50], in the cortex of Itgb $1^{\text {fff }}$; Emxl-Cre mice (Supplementary information, Figure S7). The upregulation of ILK may reflect homeostatic intracellular responses to the loss of Itgb1. Next, we determined states of LKB1 and SAD kinases, which are known to be essential for axon formation both in vitro and in vivo [12-14]. Interestingly, we found that the levels of SAD kinases and phosphorylated LKB1 (pLKB1) at S431, an active form of LKB1, were markedly decreased in the hippocampus or cortex of ItgbI fff; Emxl-Cre mice (Figure 4A). In line with this observation, we found that the level of phosphorylated Tau (pTau) at S262, the consensus phosphorylation site by SAD kinases [13], was decreased in these Itgb1-deletion mice (Figure 4A). Thus, Itgb1 plays an important role in maintaining the levels or activity of 
A

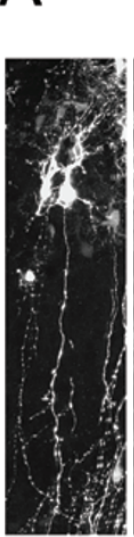
$\lg G$ beads $\left(\operatorname{|tgb} 1^{f / f}\right)$
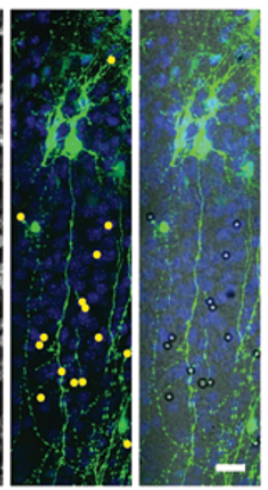

C

laminin beads $\left(\operatorname{ltgb} 1^{\mathrm{f} /+}+\right.$ Cre)
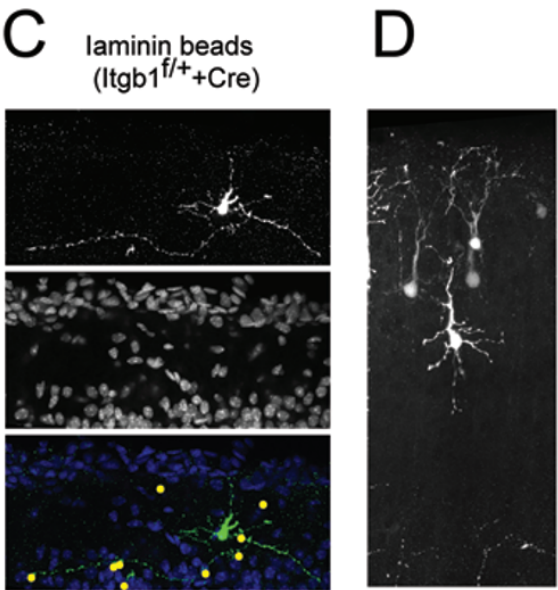

laminin beads $\left(\operatorname{ltgb} 1^{f / f}+\mathrm{Cre}\right)$
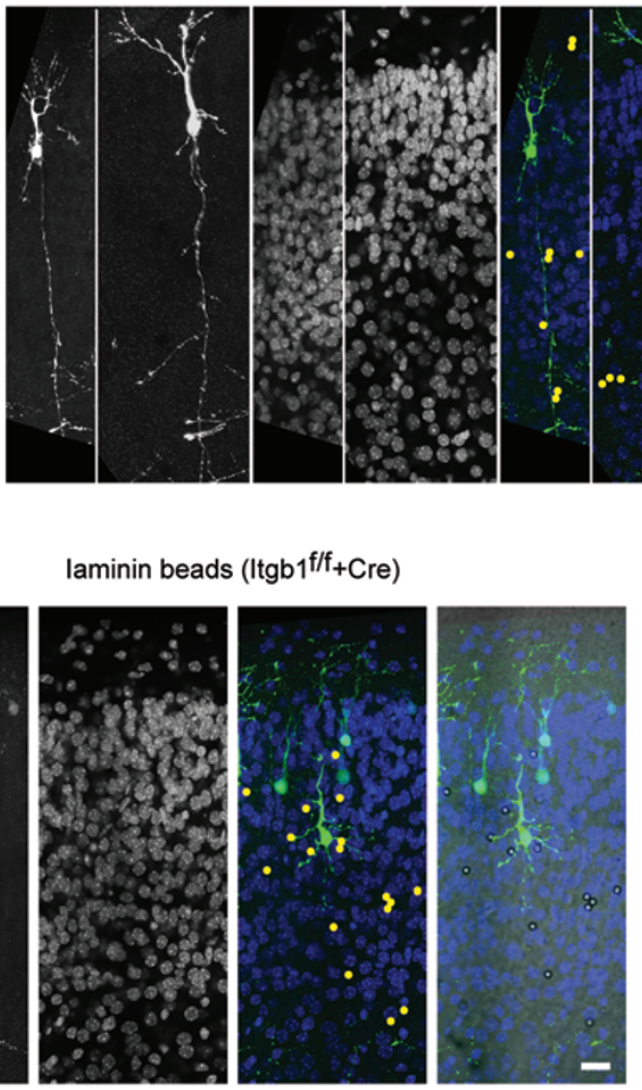
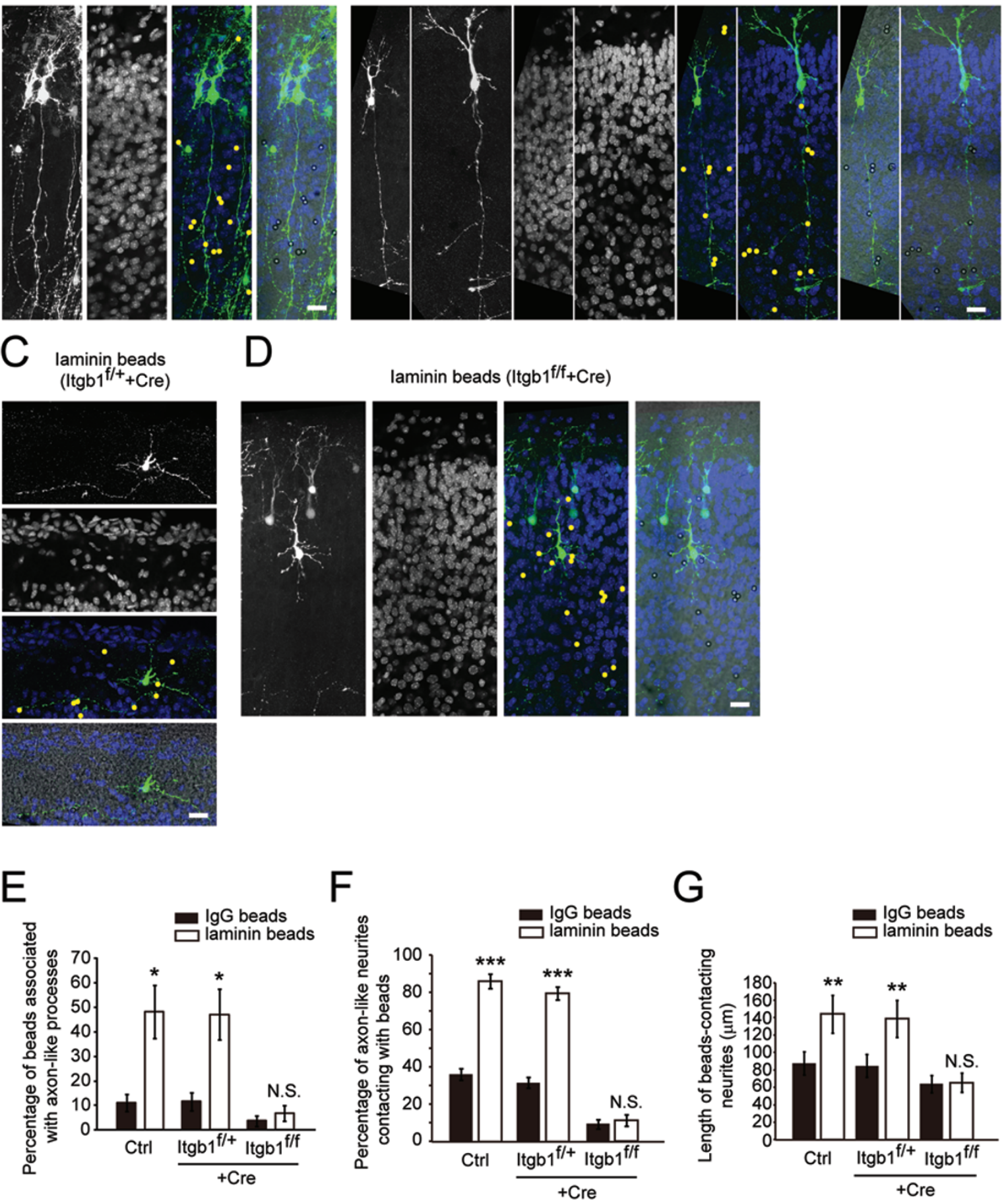

Figure 3 The oriented axon initiation is directed by laminin/ltgb1 signaling in slice culture environment. (A-D) E15.5 mice were subjected to in utero electroporation with pCAG-IRES-GFP plasmid together with vehicle plasmid or plasmid encoding Cre. Brain slices from electroporated mice were implanted with laminin- or lgG-coated beads (indicated by pseudocolored yellow). Cell layers were displayed by DAPI labeling. Shown are example images from different treatment groups. (E) Quantitative analysis for the percentage of beads associated with axon-like processes. Data are presented as mean \pm SEM from three independent experiments. At least 538 beads were analyzed for each sample per experiment. ${ }^{*} P<0.05$. (F, G) Quantitative analysis for the percentage of axon-like neurites (F) or average length of beads-contacting neurites (G). At least 216 neurites were analyzed for each group per experiment. ${ }^{* *} P<0.01$, ${ }^{* *} P<0.001$, N.S., no significant difference. Scale bars, $10 \mu \mathrm{m}$. 
polarity proteins as well as the steady-state phosphorylation of a microtubule-associated protein. To further determine the relationship between Itgb1 and these polarity proteins, we knocked down Itgb1 by siRNAs. As shown in Figure 4B, the levels of pTau (S262), pLKB1 (S431), or SAD kinases were all reduced in cultured cortical neurons that were transfected with \#4 siRNA against Itgb1, as compared to control neurons transfected with scrambled siRNA. This reduction was prevented in neurons cotransfected with \#4 siRNA-resistant h-Itgb1, indicating the specificity of siRNA in downregulation of Itgb1.

The relationship between Itgb1 and SAD kinases in regulating axon development was further examined by co-transfecting constructs encoding SAD kinases and siRNA against Itgb1 into cultured hippocampal neurons. Interestingly, the failure of axon development caused by Itgb 1 downregulation was largely prevented by co-transfection with SAD kinases (Figure 4C). This supports the notion that the levels or activity of SAD kinases are downstream of the action of Itgb1 during axon development.

\section{Laminin/Itgb1 signaling promotes MT assembly during} axon formation

Preferential microtubule stabilization in an undifferentiated neurite is sufficient to induce axon differentiation [3]. Furthermore, SAD kinases are believed to mediate axon formation by regulating microtubule-associated protein Tau $[3,13]$. Our finding of Itgb1 regulation of SAD kinases prompted us to investigate the role of laminin/ Itgb1 signaling in regulating microtubule (MT) assembly. Given that localized contact with laminin promoted axon development, we therefore assessed microtubule stability in the neurites of unpolarized neurons, when they were "on" or "off" laminin stripes during the first day in culture. The MT stability was determined by im-
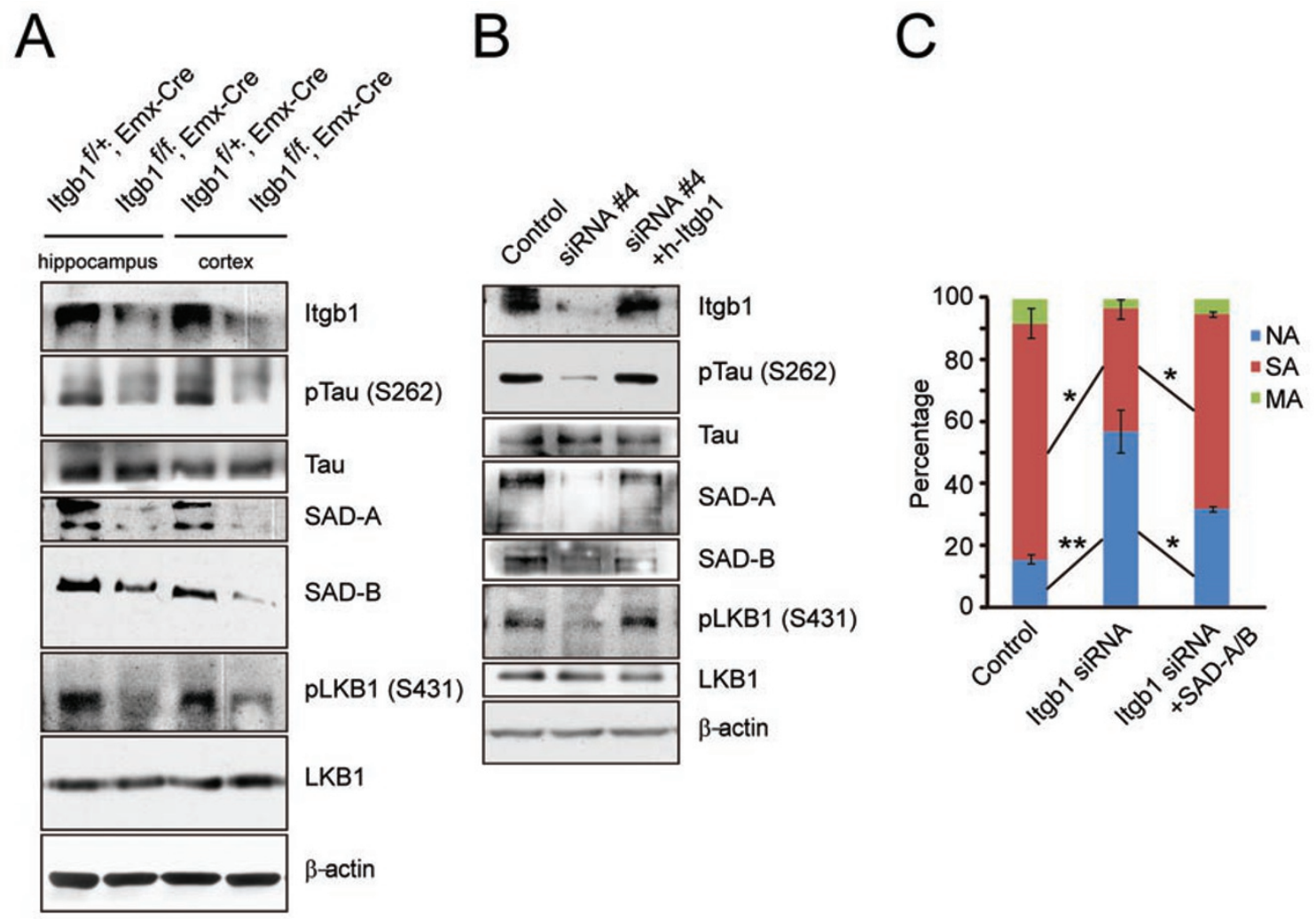

Figure 4 Loss of Itgb1 affects LKB1/SAD kinase pathway. (A) Homogenates of hippocampus or cortex from littermate P0 mice with indicated genotypes were subjected to IB with indicated antibodies. (B) Isolated cortical neurons were transfected with pSUPER plasmid or plasmids encoding Itgb1 \#4 siRNA or \#4 siRNA plus the siRNA-resistant h-Itgb1 before plating on laminin substrates. Cell lysates were subjected to IB with indicated antibodies. Blots shown are representatives of three independent experiments. (C) Isolated hippocampal neurons were transfected with plasmids encoding scrambled sequence or Itgb1 siRNA or Itgb1 siRNA plus SAD A/B kinase expression constructs and plated on laminin substrates. Neuronal polarity was analyzed at DIV3. Shown are mean \pm SEM from at least three independent experiments $(n=120$ for all experimental groups). ${ }^{*} P<0.05$. 
munostaining of acetylated and tyrosinated $\alpha$-tubulin, which mark stable and dynamic MTs, respectively [51]. We found that the on-stripe neurite exhibited a significantly higher ratio of acetylated to tyrosinated MTs (A/ $\mathrm{T}$ ratio), as compared to that of off-stripe neurites (Figure $5 \mathrm{~A}$, top row, and 5B). Interestingly, downregulation of Itgb1 expression with \#4 siRNAs prevented preferential MT stabilization, as reflected by similar $\mathrm{A} / \mathrm{T}$ ratio for on- and off-stripe neurites (Figure 5A, middle row, and 5B). Thus, contact with laminin induces preferential MT stability, a process that requires Itgb1. The specificity of the siRNA effect was shown by the finding that cotransfection of siRNA-resistant h-Itgb1 with \#4 siRNA restored the high $\mathrm{A} / \mathrm{T}$ ratio in on-stripe neurites (Figure $5 \mathrm{~A}$, bottom row, and $5 \mathrm{~B}$ ). Thus, laminin/Itgb1 signaling induces MT stabilization, a process capable of triggering axon formation in hippocampal neurons [3].

The assembly of MTs involves polymerization at the plus end, which can be analyzed by visualizing the motion of plus end-binding proteins, such as EB1 or EB3 [52]. Hippocampal neurons were transfected with EGFPEB3 before plating on substrates coated with laminin stripes, and the trafficking of EGFP-EB3 puncta was monitored by time-lapse fluorescence microscopy for all neurons with the soma located at the stripe boundary (Figure 5C). We classified EB3 movements into three categories: retrograde (towards the soma), anterograde (away from the soma), and immobile. As shown by the kymographs in Figure 5C (also see Supplementary information, Movie S1), moving EB3 puncta were predominantly anterograde in on-stripe neurites (see c1), but not in off-stripe neurites (see c2). In addition, the average velocity of EB3 puncta was higher in on-stripe neurites than in off-stripe neurites (Figure 5E). These results suggest that contact with laminin results in preferential assembly of MTs with plus-end towards the distal end of the neurite. The role of Itgb1 in EB3 trafficking was further shown by the effect of downregulation of Itgb1 in these neurons. We found that transfection with Itgb1 siRNA caused a decrease in anterograde transport and an increase in retrograde transport of EB3 puncta in on-stripe neurites (Figure 5C and Supplementary information, Movie S2), with the velocity and the distribution of three categories of puncta indistinguishable from that of offstripe neurites (Figure 5C-5E). Thus, Itgb1 is necessary for directional microtubule assembly induced by laminin.

\section{MT stabilization prevents axon formation defects due to Itgb1 downregulation}

Having determined the role of laminin/Itgb1 signaling in MT assembly in polarizing neurons, we next investigated whether MT stabilization itself may compensate the loss of axon formation due to Itgb1 downregulation. Axon formation in cultured hippocampal neurons is known to be promoted by manipulations of cytoskeletal structures using appropriate concentrations of actin filament depolymerizing drugs, such as $1 \mu \mathrm{M}$ of cytochalasin D or latrunculin A [4], or MT-stabilizing drugs, such as 3-10 nM of taxol [3]. We found that all these treatments increased the percentage of cultured hippocampal neurons bearing MA (Figure 6A, 6B and Supplementary information, Figure S8B). Interestingly, treatment with taxol $(2 \mathrm{nM})$ partially rescued axon development that was impaired in neurons with Itgb1 downregulation (Figure $6 \mathrm{~A}$ and $6 \mathrm{~B}$ ) or treated with Itgb1 function-blocking antibodies (Supplementary information, Figure S8A and S8B), but treatments with cytochalasin D or latrunculin A had no rescue effect. These results are consistent with the axon induction effect of MT-stabilizing drugs [3], and support the notion that MT stabilization mediates the axon promotion effect of laminin/Itgb1 signaling.

\section{Itgb1 is required for axon formation in cortical neurons in vivo \\ Global deletion of $\operatorname{Igb} 1$ in mice results in lethality during early post-implantation $[35,36]$. We thus exam-}

Figure 5 Itgb1 is essential for laminin-induced microtubule stabilization and assembly during neuronal polarization. (A) Isolated hippocampal neurons were transfected with indicated plasmid combinations (scrambled siRNA, Itgb1 siRNA, or Itgb1 siRNA plus h-ltgb1) and cultured on substrates coated with laminin stripes (blue). Transfected neurons at DIV2 were stained with antibodies against acetylated (Acet-, green) and tyrosinated (Tyr-, red) - $\alpha$-tubulin. Scale bar, $10 \mu \mathrm{m}$. (B) Quantification for the ratio of Acet- to Tyr-Tubulin (A/T) for neurites on- (indicated by arrows) or off-stripes (indicated by arrowheads), with the value from on-stripe control neurites normalized as 1.0. Data are shown as mean \pm SEM from three experiments. At least 30 neurites were analyzed for each group. ${ }^{* * *} P<0.001$, Student's $t$-test. (C) Hippocampal neurons were transfected with EGFPEB3, together with plasmids encoding scrambled siRNA or Itgb1 siRNA, were cultured on substrates coated with laminin stripes. Scale bar, $10 \mu \mathrm{m}$. At DIV2, movement of individual EGFP-EB3 puncta was recorded using live-imaging fluorescence microscope. Shown are representative kymographs for on-stripe neurites (c1, c3) or off-stripe neurites (c2, c4), in neurons without or with Itgb1 downregulation. (D) Percentage of anterograde, retrograde, or immobile EGFP-EB3 comets, for neurites on- or off-laminin stripes, in neurons without or with Itgb1 downregulation. ${ }^{*} P<0.05,{ }^{* *} P<0.01$ vs control, ANOVA with Student's $t$-test. (E) Quantification for the velocity of EB3 puncta of indicated groups. ${ }^{*} P<0.05$ vs control on-stripe. 
A

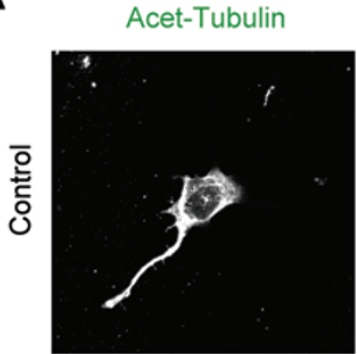

Tyr-Tubulin

Merge ( laminin )
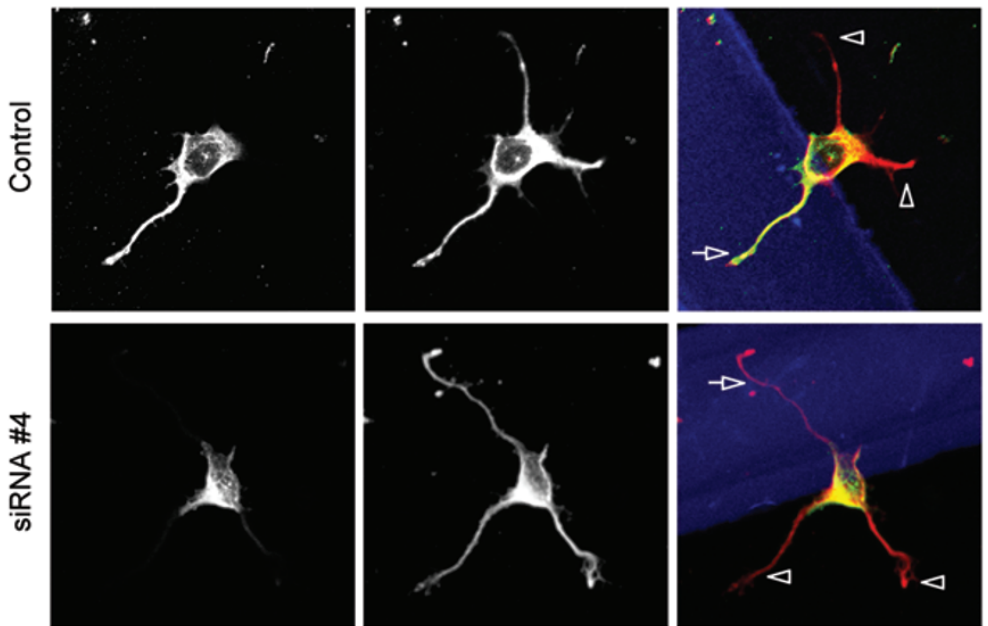

B
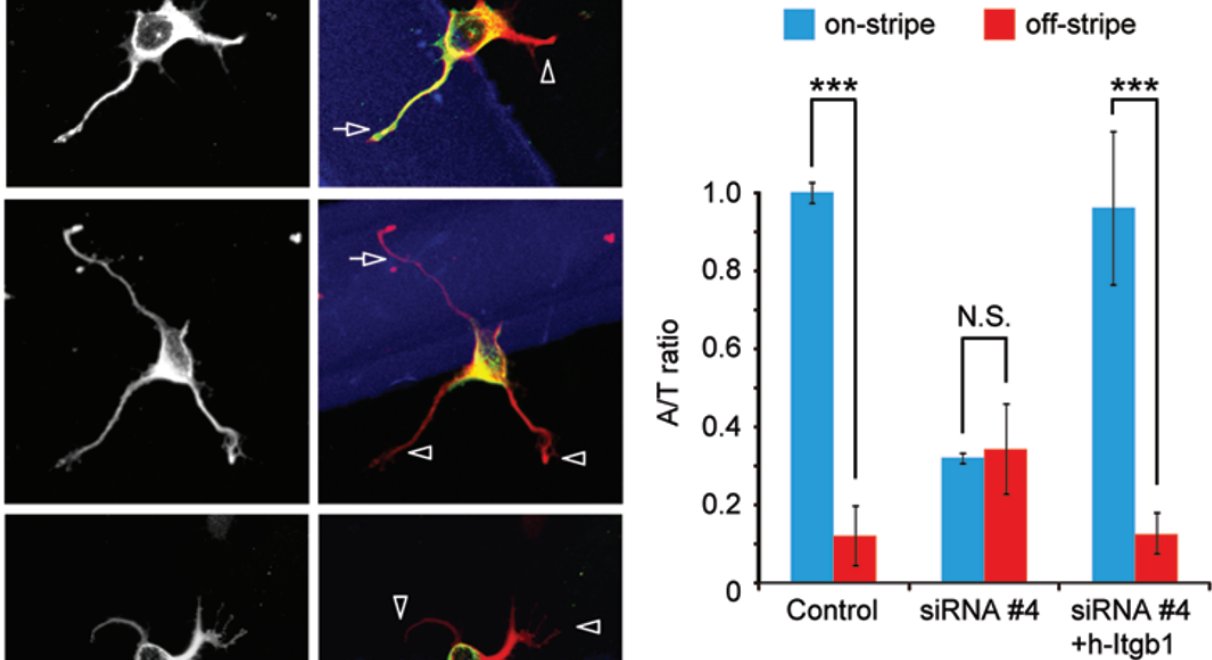

on-stripe $\square$ off-stripe
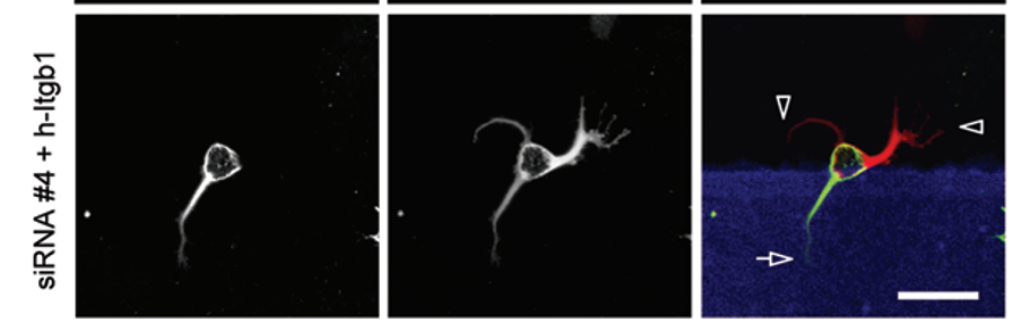

$\mathcal{C}$

EGFP-EB3/laminin

c1. Ctrl neurite on-stripe

c2. Ctrl neurite off-stripe
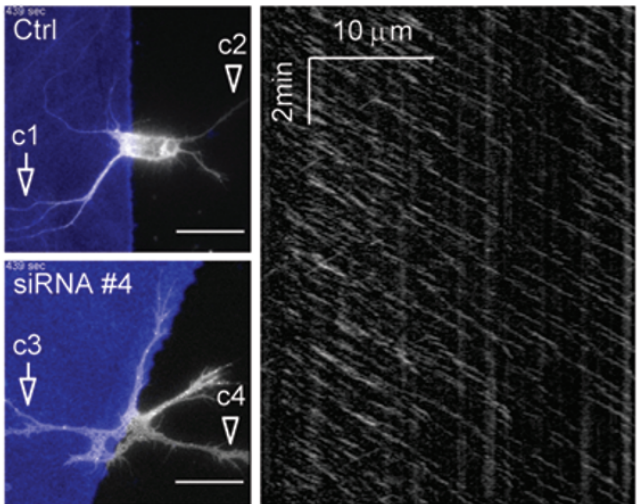

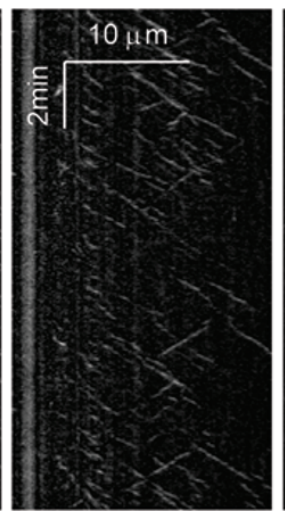

c3. Itgb1 siRNA \#4 neurite on-stripe
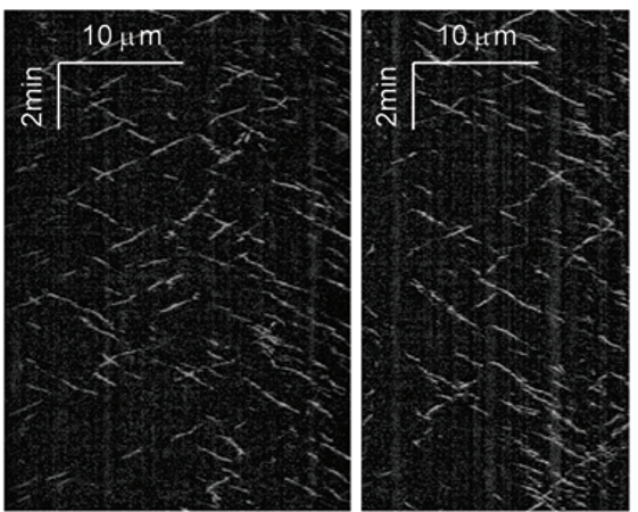

D

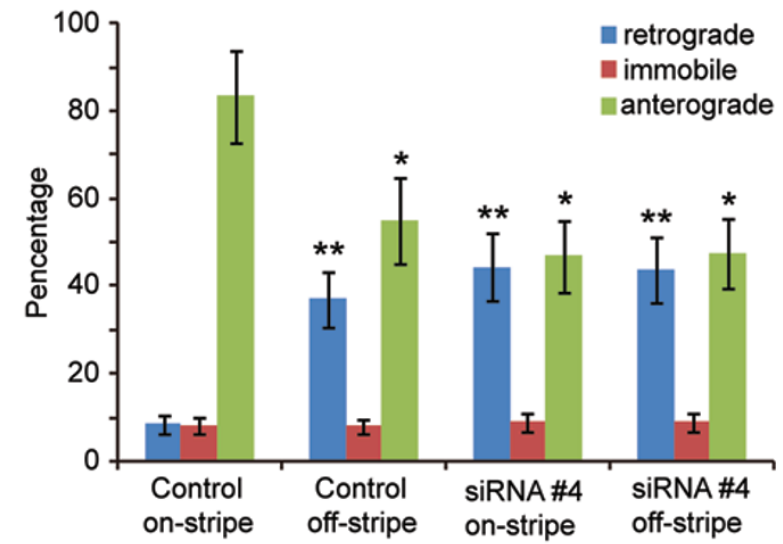

E

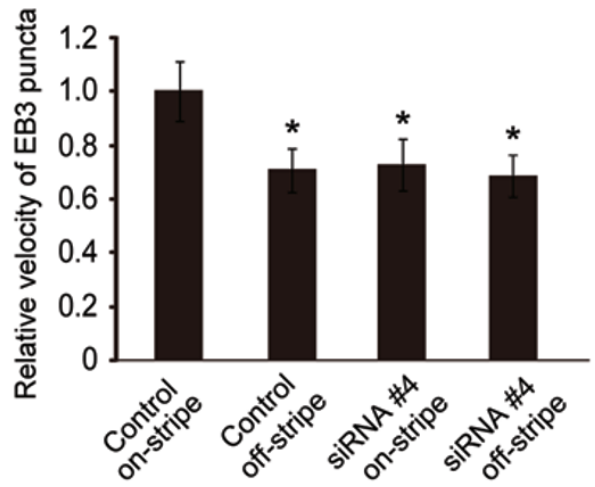




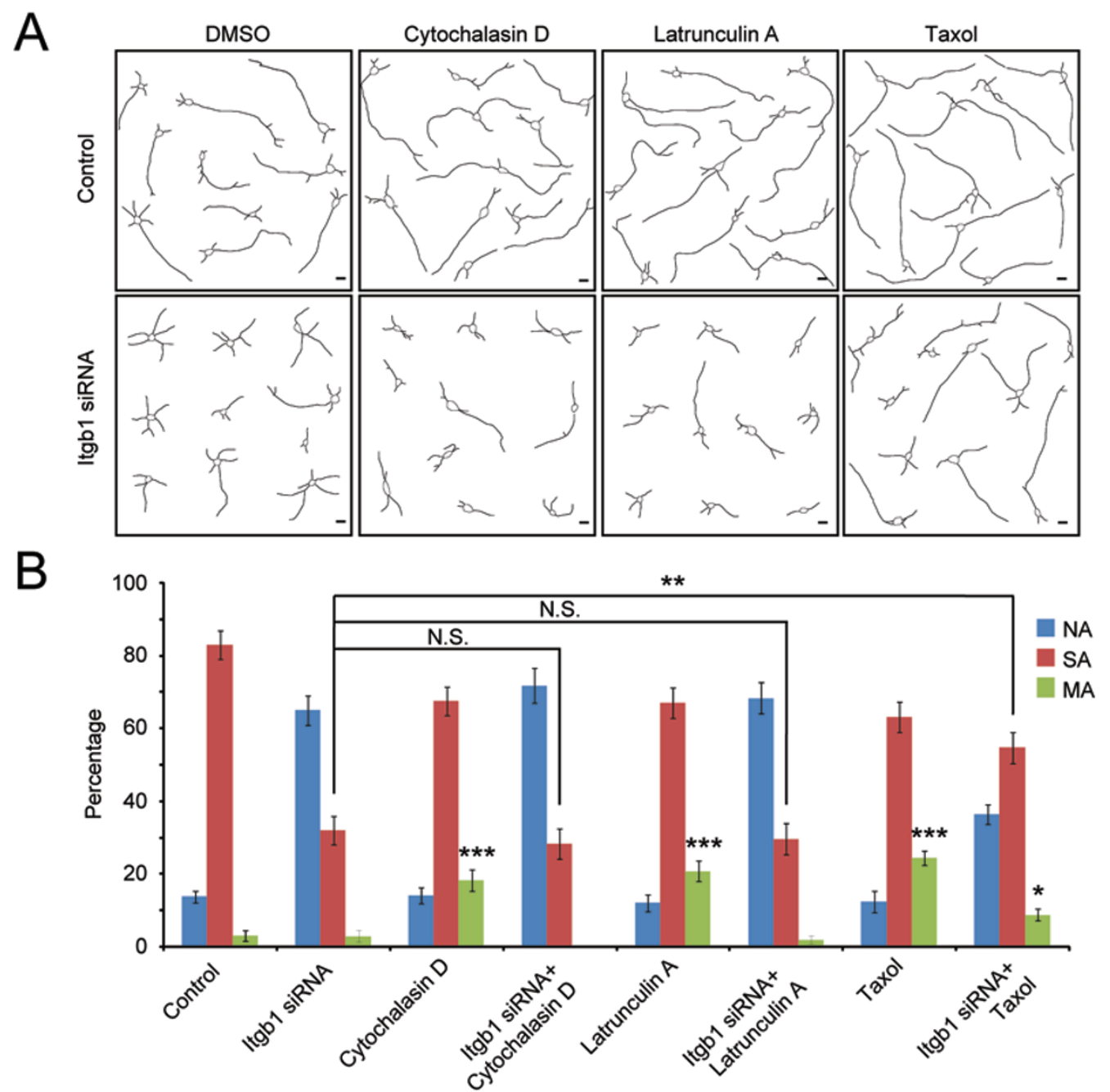

Figure 6 Taxol stabilization of microtubules partially prevents the loss of neuronal polarity caused by Itgb1 downregulation. (A) Hippocampal neurons were transfected with pSUPER plasmid encoding scrambled or Itgb1 siRNA, and then treated with cytochalasin $\mathrm{D}(1 \mu \mathrm{M})$, latrunculin $\mathrm{A}(1 \mu \mathrm{M})$, or taxol $(2 \mathrm{nM})$ at DIV1 for $12 \mathrm{~h}$. Shown are representative reconstructed images of EGFP-positive neurons from different groups. Scale bar, $10 \mu \mathrm{m}$. (B) Quantification for neuronal polarity. Note that treatments with cytochalasin $\mathrm{D}$, latrunculin $\mathrm{A}$, or taxol all increased the percentage of neurons with $\mathrm{MA}\left({ }^{* \star \star} P<0.001\right.$ vs control). Taxol treatment significantly increased the percentage of neurons with SA and MA in Itgb1 siRNA-transfected neurons ( ${ }^{* *} P<0.01$, ${ }^{*} P<0.05$, Itgb1 siRNA vs Itgb1 siRNA plus taxol).

ined the effect of partial and complete elimination of Itgb1 in dorsal telencephalic progenitors by crossing the $\operatorname{Itg} b 1^{f f}$ or Itgb1 $1^{f / 4}$ mice [37] with the Emx1-Cre transgenic mice [38], respectively. As shown in Figure 4A, the Itgb1 protein level was markedly reduced in the cortex and hippocampus of the Itgbl fff; Emxl-Cre mice compared to $\operatorname{Itg} b 1^{f / 4}$; Emxl-Cre mice. In agreement, the amount of phosphorylated focal adhesion kinase (pFAK) at T397, an active form of FAK, was decreased in $\operatorname{Itgbl}^{\text {fff }}$; Emx1-Cre mice (Supplementary information, Figure S7), suggesting the inhibition of integrin-mediated focal adhesion signaling. Consistent with previous reports of restricted Itgb1 elimination in post-mitotic neurons [23, 24], we found that both the cortex size and lamination were roughly normal in Itgb ${ }^{f f f}$; Emx1-Cre or Itgb $1^{f /+}$; Emx1-Cre mice (Supplementary information, Figure S9).

To determine whether loss of Itgb1 in cortical neurons causes axonal defect, we first implanted crystals of fluorescent lipid DiI (1,1'-dioctadecyl-3,3,3',3'tetramethylindocarbocyanine perchlorate) into the cortex to trace cortical axons [39]. In the control $\left(\operatorname{Itg} b 1^{\text {fff }}\right)$ or $\operatorname{Itgb1^{f/+}}$; Emx1-Cre mice, we found that DiI-labelled corticofugal axons descended from the cortex and projected towards either external capsule (arrowheads in Figure 7A, 
see $\mathrm{a} 2$ and a4) or corpus callosum that crossed the midline (arrows in Figure 7A, see a1 and a3). However, these axon projections were severely affected in $\operatorname{Igbl}^{\mathrm{ff}}$; EmxlCre mice. Due to the variability of DiI labeling, we also examined axon development by staining with antibody against TAG1, a cell adhesion molecule that marks corticofugal axons [41]. As shown in Figure 7B, control mice at E18.5 show normal callosal axons crossing the midline (see b1) and lateral projection through the external capsule (see b2). Remarkably, the TAG1-positive signals were severely impaired in age-matched Itgbl $1^{f f f}$; EmxlCre mice (Figure 7B, see b3 and b4). We also analyzed axon development in E14.5 mice, when callosal axons have not formed. As shown in Supplementary information, Figure S10, while TAG1-positive axons were seen in the neocortex of control mice, these axons were barely detectable in E14.5 mutant mice. Of note, $\mathrm{NgCAM} / \mathrm{L} 1$, another marker for corticofugal axons, was not affected in Itgb1 mutant mice (data not shown), probably due to unresponsiveness of another set of cortical neurons to Itgb1 manipulation. Nevertheless, the above results support the notion that Itgb1 signaling plays an important role in neocortical axon development in vivo.

The above axon defects could result from the effect of Itgbl gene deletion in radial glial cells, which are known to be affected in the Itgbl fff; nestin-Cre mice [23, 24, $45,46]$. We thus performed single cell gene elimination experiment by using in utero electroporation method at E15.5 [47]. The Itgb $1^{f / 4}$ and $\operatorname{Itg} b 1^{f f}$ mice were electroporated with Cre-containing plasmid (pTurbo-Cre) together with pCAG-IRES-EGFP as neuronal marker (termed "Itgb1 $1^{f / 4}-C r e$ " and "Itgbl $\left.1^{f / f}-C r e "\right)$, and the $\operatorname{Itgb} 1^{f f f}$ mice electroporated with pCAG-IRES-EGFP alone was used as the control. After electroporation, coronal sections of the cortex at P3 were analyzed for neuronal morphology. We found that majority of cortical neurons transfected with the control vector pCAG-IRES-EGFP migrated to upper layers and exhibited normal axon projection toward
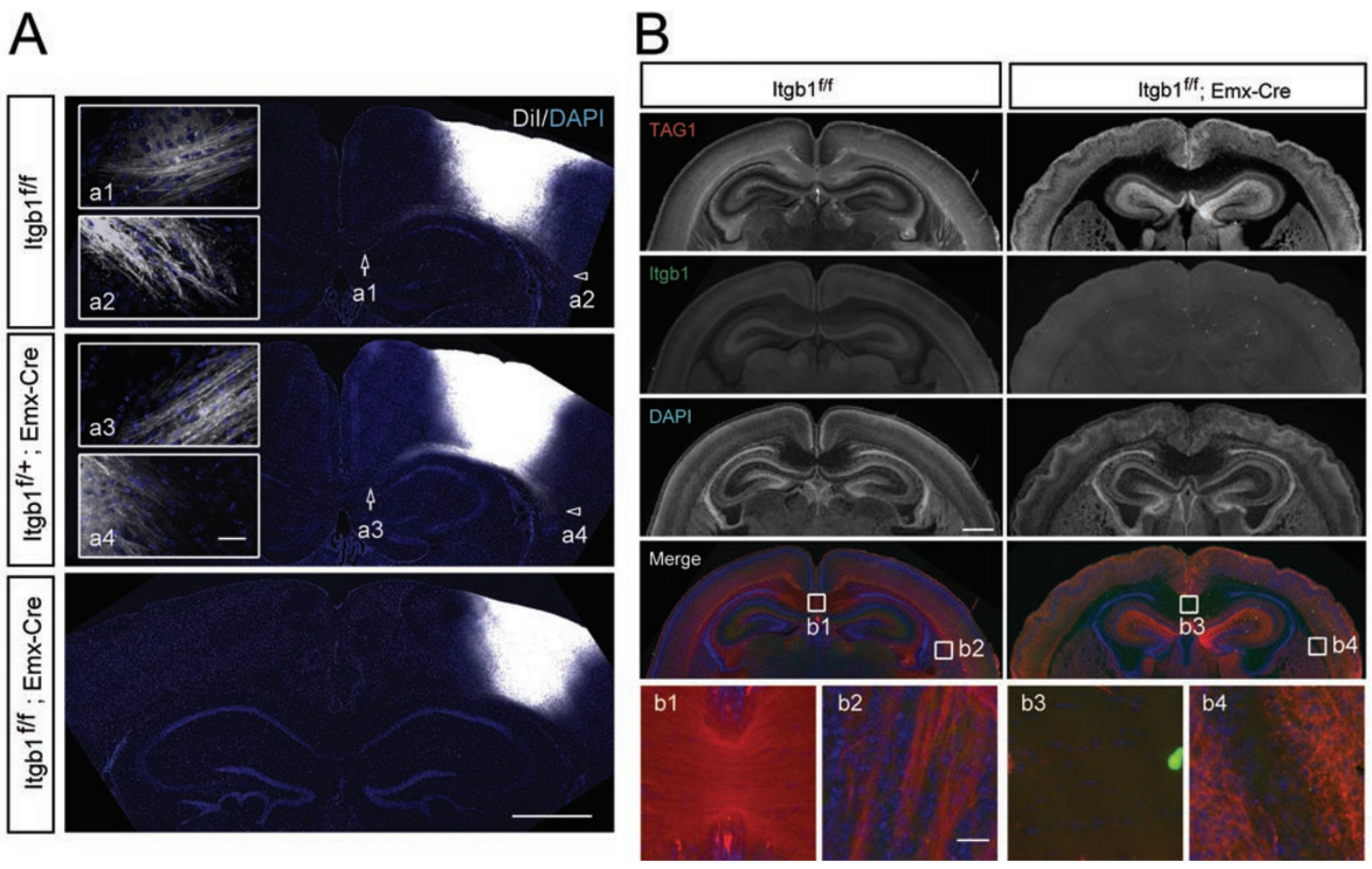

Figure 7 Essential role of Itgb1 in axon development in vivo. (A) Dil crystals were placed in the somatosensory cortex of control $\left(\operatorname{Itg} b 1^{f / f}\right)$ or mutant mice $\left(\operatorname{Itg} b 1^{\mathrm{f} / f}\right.$; Emx1-Cre or Itgb $1^{f /+}$; Emx1-Cre) at P3. Coronal sections reveal descending tracts toward the corpus callosum (arrows) or internal capsule (arrowheads). Cell layers were displayed by DAPI labeling. The magnified images (10×) show axon fibers in medial (a1 and a3) and lateral (a2 and a4) projections, respectively. (B) Cortical sections of control $\left(\operatorname{Itg} b 1^{f / f}\right)$ and Itgb1 mutant $\left(\operatorname{Itg} b 1^{f / f} ; E m \times 1-C r e\right)$ mice at P0 were stained with antibody to TAG1. The magnified images $(5 \times)$ at the bottom show axon fibers in corpus callosum (compare b1 and b3) and internal capsule (compare b2 and b4), respectively. Scale bars, $2 \mathrm{~mm}$ and $50 \mu \mathrm{m}$ (insets) in A, $1 \mathrm{~mm}$ and $100 \mu \mathrm{m}$ (insets) in B. 

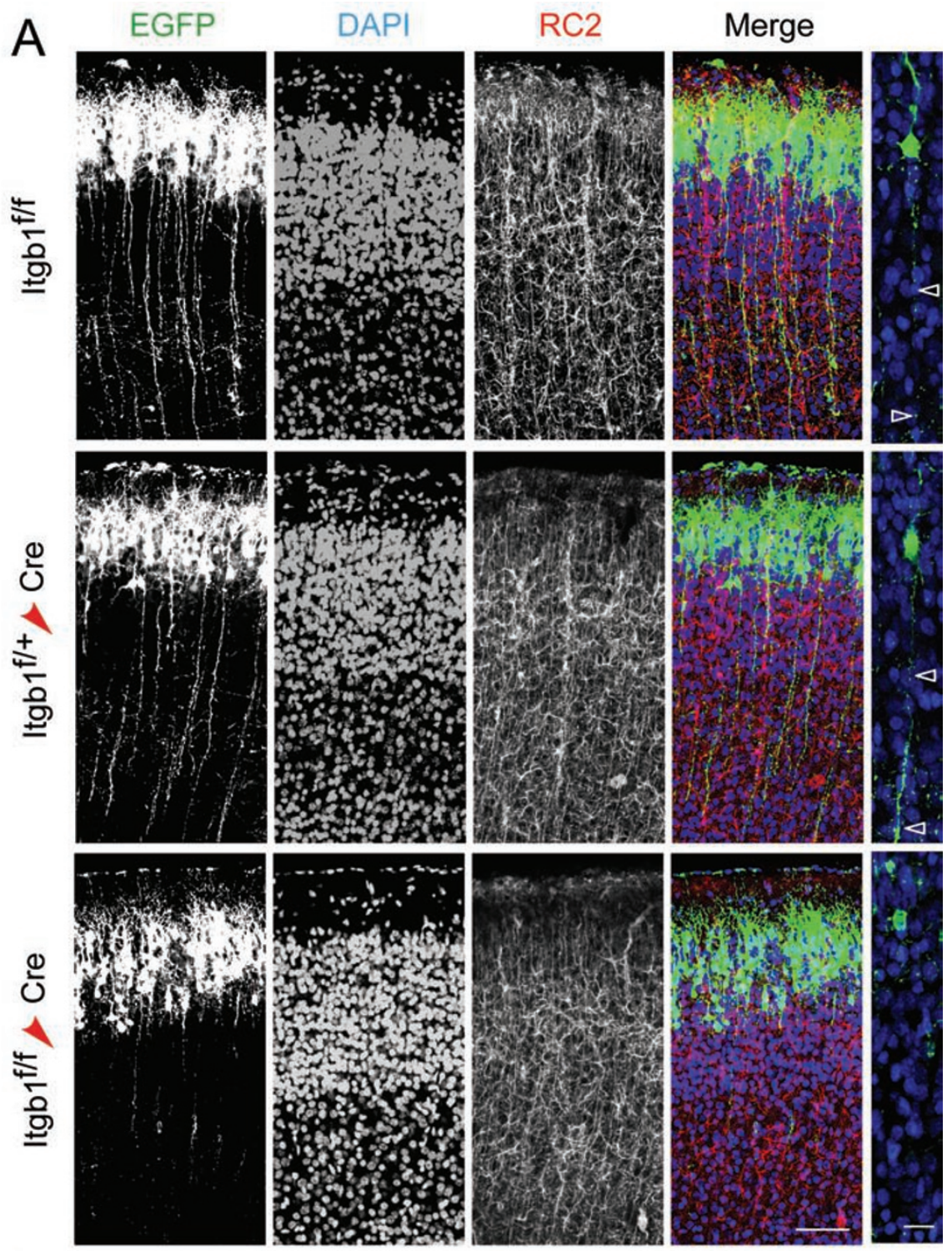

B

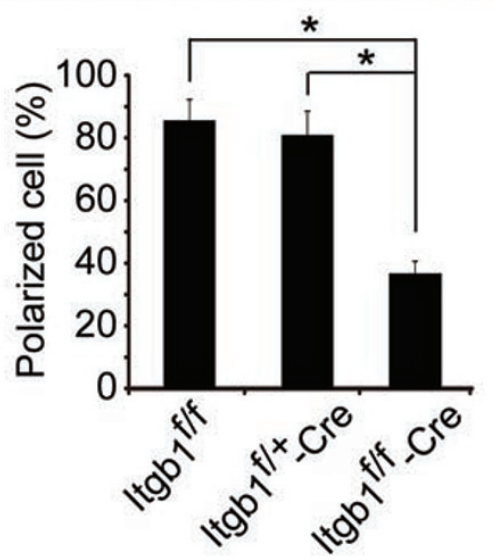

Figure 8 Cell autonomous role of Itgb1 in axon initiation in vivo. (A) $\operatorname{ltg} b 1^{f / f}$ or $\operatorname{ltg} b 1^{f / 4}$ mice at E15.5 were subjected to in utero electroporation with pCAG-IRES-GFP plasmid together with vehicle plasmid or plasmid encoding Cre. Cortical sections from P3 mice were stained with antibody against radial glia marker RC2 and cell layers were marked by DAPI labeling. Right lane images show single cell morphology. (B) Quantification for the percentage of polarized neurons in the cortical plate with a long thin descending axon ( $n=80$ for all groups). Scale bars, $100 \mu \mathrm{m}$ (left four lanes) or $10 \mu \mathrm{m}$ (right lane). ${ }^{\star} P<0.05$. 
the ventricular surface (Figure 8A, top row). Given that laminin/integrin signaling may act during neurogenesis to provide the stem cell niche [48], we only analyzed morphology of neurons that already reached the cortical plate at P3 and exhibited positive staining for neuronal marker Tuj1 (Supplementary information, Figure S11). We found that ablation of Itgb1 caused a marked reduction in the percentage of axon-bearing neurons, which had only short apical dendrite-like processes (Figure 8A, bottom row), confirming the importance of Itgb1 signaling in axon formation. Expression of Cre in $\operatorname{Itg} 1^{f /+}$ mice had no effect on neuronal polarization (Figure 8A, middle row), excluding the potential toxic effect caused by Cre expression. Furthermore, staining with radial gliaspecific marker RC2 showed roughly normal radial glial networks in all experimental groups (Figure 8A, lane 3), suggesting that the impairment of axon formation caused by Itgbl gene deletion in ItgbI ${ }^{\mathrm{fff}}$; Emxl-Cre mice was due to a cell autonomous mechanism.

\section{Discussion}

ECM protein laminin is known to promote axon development of cultured neurons $[1,17,18]$, but the linkage between the laminin signaling and the known intracellular mechanisms underlying axon formation has not been established. Here we report that laminin's action in promoting axon development is mediated by MT stabilization in undifferentiated neurite triggered by laminin/Itgb1 signaling. Furthermore, we examined the role of Itgb1 in vivo, and found that Itgb1 conditional knockout mice exhibited severe defects in axon development of a subset of cortical neurons, and abnormal expression or activity of neuronal polarity proteins, including SAD and LKB1 kinases. Furthermore, we demonstrated that laminin/Itgb1 signaling promotes MT stabilization, as indicated by the $\mathrm{A} / \mathrm{T} \alpha$-tubulin ratio and anterograde transport of EB3. Pharmacological enhancement of MT stabilization partially rescued the axon development in Itgb1-downregulated neurons. Thus, we have demonstrated a laminin/ Itgb1-dependent cytoskeletal mechanism for promoting neuronal polarization.

\section{Essential role of laminin/integrin signaling in axon formation}

Undifferentiated neurites of cultured hippocampal or cortical neurons showed higher probability of axon differentiation when they are in contact with laminincoated stripes [18]. The integrin $\alpha 6 \beta 1$ heterodimer is expressed at a high level in the apical region of VZ [19]. Laminins, which serve as ECM ligands for integrins, are also present in the VZ [19]. The following lines of evidence support the essential role of laminin/ integrin signaling in establishing neuronal polarity: First, laminin-coated substrates, in either stripes or in a gradient, or laminin-coated beads could specify axon initiation site from the soma in an Itgb1-dependent manner (Figures 1-3). Second, disrupting the action of endogenous laminin by supplying exogenous laminin or downregulating Itgb1 by specific treatments with siRNAs abolished directional axon extension in a slice overlay assay (Figure 2). Third, ablation of the Itgbl gene or downregulation of Itgb1 signaling in cortical neurons resulted in defects in axon formation and neuronal polarity in vivo (Figures 7 and 8) and the loss of responsiveness of cortical neurons towards axon induction by laminin-coated beads (Figure 3). Finally, Itgb1 activation by antibody cross-linking was sufficient to induce the formation of MA and promotion of axon growth in hippocampal cultures (Figure 1D and 1E).

A recent report shows that the laminin/integrin signaling is necessary for maintaining neocortical stem cell niche and the orientation of neural stem cell division [48]. Thus, neuroepithelial cell polarity may be causally related to postmitotic neuron polarity [2], i.e., postmitotic neurons directly inherit the intrinsic apico-basal polarity of their progenitors, which are determined by laminin/ integrin signaling. The relative importance of laminin/ integrin signaling in polarity formation before and after last mitotic division remains to be further studied.

\section{Laminin/Itgb1 signaling and neuronal polarity proteins}

Many polarity proteins involved in apico-basal polarity of neuroepithelial progenitors in the neocortex, e.g., those in the apical polarity complex aPKC/Par3/Par6, and $\mathrm{Cdc} 42$ [53-55], are also required for axon specification $[56,57]$. The relationship between integrin signaling with some of these polarity proteins has been established in astrocyte polarization and migration [58] - the interaction of integrins with ECM at the newly formed cell front leads to the activation and polarized recruitment of $\mathrm{Cdc} 42$, which in turn recruits and activates the cytoplasmic mPar6/PKC $\zeta$ complex, which further modifies MT cytoskeleton. In this study, we found that the loss of Itgb1 caused inactivation of the Par4 homolog LKB1 and downregulation of Par1 homolog kinases SAD-A and B, all of which are necessary for axon formation in vivo [1214]. Furthermore, overexpression of SAD-A and B was found to partially compensate the loss of axon formation due to downregulation of Itgb1. The partial effect may be attributed to involvement of other polarity proteins in mediating laminin/Itgb1 signaling. Alternatively, the level or distribution of overexpressed SAD-A/B was not optimal for compensating the laminin/Itgb1 signaling. 
How might laminin/integrin regulate $\mathrm{LKB} 1$ or $\mathrm{SAD}$ kinases? Our results show that the loss of Itgb1 caused a decrease in the phosphorylation of LKB1 at Ser 431, a consensus site for cAMP-dependent protein kinase (PKA), and the level of SAD-A/B (Figure 4). In line with this finding, a previous report shows that integrin $\alpha 4$ cytoplasmic domain acts as a type I PKA-specific kinase-anchoring protein (AKAP), which controls the localization and substrate specificity of PKA [59]. Thus, laminin/integrin signaling may regulate PKA-dependent phosphorylation of LKB1 via recruitment or activation of AKAP, and phosphorylated LKB1 further exerts its kinase action on the activity or stability of SAD kinases.

\section{Laminin/integrin signaling in microtubule assembly}

Integrin signaling has been proposed to reorganize cytoskeletal structure in non-neuronal cells. For example, integrin-mediated activation of focal adhesion kinase at the leading edge of mouse fibroblasts is required for MT stabilization by the Rho signaling pathway [58]. During cell mitosis, integrin-mediated adhesion also orients the spindle parallel to the substratum, a process requiring Factin and astral MTs [60]. Furthermore, perturbing Itgb1 function inhibits MT growth from centrosomes and the assembly of the mitotic spindle during cytokinesis [61]. In this study, we found that contact with laminin-coated substrate caused stabilization of MT assembly and elevated anterograde transport of plus-end binding protein EB3 (Figure 5), both of which are likely to promote axon initiation and growth. These results establish a direct linkage between ECM-mediated adhesion and cytoskeleton remodeling, and the function of this linkage in axon formation.

In addition to the ECM, a number of extracellular axon-promoting factors have been identified, such as netrin [62], BDNF [14], Sema3a [63], Wnt [57], and TGF $\beta$ [15]. Some of these factors interact with integrin signaling during cell proliferation [64], adhesion and migration [65-67], neurite outgrowth, and growth cone guidance [68-70]. It is thus possible that other extracellular cues execute their roles through modulating integrin signaling directly or indirectly. Thus, the mechanism of laminin/ Itgb1-triggered MT assembly and stability may also be relevant for neuronal polarization induced by other factors that interact with integrins.

\section{Materials and Methods}

\section{Reagents, antibodies and constructs}

Substrates coated on coverslips or culture dishes, including poly-D-lysine hydrobromide, collagen, fibronectin, and laminin were purchased from Sigma Aldrich. Bovine serum albumin (BSA) conjugated with AlexaFluor 488/555/647 was used to vi- sualize substrate stripes and surface-bound protein gradients and purchased from Invitrogen. Cytochalasin D, latrunculin A, and paclitaxel (taxol) were from Sigma Aldrich. Antibodies used for immunostaining were: rabbit anti-GFP from Invitrogen; rat antiGAP43 from Calbiochem; mouse anti-Smi312 from Covance; rabbit anti- $\beta 2$ laminin and rabbit anti-Cux1 from Santa Cruz Biotechnology; mouse anti-acetylated tubulin and mouse anti- $\beta$ tubulin III (Tuj1) from Sigma Aldrich; mouse anti-Itgb1 (HUTS4), mouse anti-RC2, and rabbit anti-MAP2 from Merck Millipore; mouse anti-L1, rat anti-tyrosinated tubulin (YL1/2), rabbit antiTAG1, and rabbit anti-Tbr1 from Abcam. Antibodies used for western blot were: rat anti-Itgb1 from R\&D Systems; rabbit antiFAK from Abcam; rabbit anti-pTau (S262) from Biosource; mouse anti-Tau from Calbiochem; rabbit anti-pLKB1 (S431) from Santa Cruz Biotechnology; mouse anti-LKB1 from Upstate; mouse anti-ILK from BD Pharmingen; mouse anti-GAPDH from KangChen; mouse anti-pAKT (S473) and rabbit anti-AKT from Cell Signaling Technology; mouse anti- $\beta$-actin and rabbit antipFAK (T397) from Merck Millipore. Polyclonal antibodies against SAD-A and SAD-B were generated in our laboratory. Antibody used to activate Itgb1 (9EG7) was from BD Pharmingen. Itgb1 function-blocking antibodies were from Abcam (P5D2) and BD Pharmingen (HM $\beta 1-1$ ). To generate pSUPER-encoded siRNAs, double-stranded oligonucleotides encoding Itgb1 siRNA were subcloned into BglII- and HindIII-digested pSUPER (OligoEngine, Seattle, WA, USA). The siRNA sequences against Itgb1 were: \#1, 5'-CCAGAGGCTCTCAAACTATTT-3' (sense) and 5'-ATAGTTTGAGAGCCTCTGGTT-3' (anti-sense); \#2, 5'-GGAGGATTACTTCAGACTTTT-3' (sense) and 5'-AAGTCTGAAGTAATCCTCCTT-3' (antisense); \#3, 5'-CCAGACGGAGTAACAATAATT-3' (sense) and 5'-TTATTGTTACTCCGTCTGGTT-3' (antisense); \#4, 5'-CCAAATAAGGAGTCTGAAATT-3' (sense) and 5'-TTTCAGACTCCTTATTTGGTT-3' (antisense). All the oligonucleotides were synthesized by Shanghai GenePharma (Shanghai, China). The human Itgb1 construct was a gift from Dr Mara Brancaccio (University of Torino, Italy).

\section{Neuronal culture, electroporation and treatments}

Dissociated hippocampal neurons were prepared as described previously [54]. Briefly, hippocampi from E18 rat embryos were digested with $0.125 \%$ trypsin-EDTA for $20 \mathrm{~min}$ at $37^{\circ} \mathrm{C}$, followed by trituration with pipettes in the plating medium (DMEM with $10 \%$ FBS and 10\% F12). Dissociated neurons were transfected by electroporation using the Amaxa Nucleofector device. In some experiments, testing plasmids were cotransfected with pEGFP at a ratio of $4: 1$. Control and transfected neurons were plated onto coverslips coated with poly-D-lysine $(0.1 \mathrm{mg} / \mathrm{ml})$ without or with laminin stripes. After culturing for $24 \mathrm{~h}$, media were changed into neuronal culture media (neurobasal media containing $1 \%$ glutamate and 2\% B27). Sometimes, neurons at DIV 1 were treated with cytoskeleton-manipulating drugs or Itgb1 activation or function-blocking antibodies at following concentrations: cytochalasin D $(1 \mu \mathrm{M})$, latrunculin A $(1 \mu \mathrm{M})$, taxol $(2 \mathrm{nM}), 9 \mathrm{EG} 7(2 \mu \mathrm{g} / \mathrm{ml})$, P5D2 $(25 \mu \mathrm{g} / \mathrm{ml})$, HM $\beta 1-1(10 \mu \mathrm{g} / \mathrm{ml})$.

\section{Immunostaining}

Neurons were first washed with PBS, then fixed in 4\% paraformaldehyde at room temperature for $30 \mathrm{~min}$, and incubated with $0.1 \%$ Triton X-100 in PBS for 10 min. After blocking with $10 \%$ 
goat serum in PBS at room temperature for $1 \mathrm{~h}$ or $4^{\circ} \mathrm{C}$ overnight, neurons were incubated in primary antibodies at $4{ }^{\circ} \mathrm{C}$ for more than $12 \mathrm{~h}$ and subsequently with Alexa Fluor 350-, 488-, 555-, 647-, CY2-, CY3-, CY5, FITC- or rhodamine-conjugated secondary antibodies. Coverslips were mounted with fluorescent mounting medium from Dako and examined under a Nikon Neurolucida system, a Zeiss confocal microscope or a Nikon confocal microscope.

For mouse brain tissues, coronal cryostat sections of $30 \mu \mathrm{m}$ were cut with a freezing microtome and immediately processed for immunostaining by a free-floating protocol (at $4{ }^{\circ} \mathrm{C}$ ). Briefly, brain slices, after treatment with $0.1 \%$ Triton $\mathrm{X}-100$ and $10 \%$ goat serum in PBS for $1 \mathrm{~h}$, were incubated in primary antibodies for $24 \mathrm{~h}$, followed by $3 \times$ washes with PBS, incubation with biotinconjugated secondary antibodies, and finally in CY2- or CY3conjugated streptavidin before observation.

\section{In utero electroporation}

In utero electroporation was performed as described previously [47]. Briefly, 1-2 $\mu \mathrm{g}$ plasmid mixed with Fast Green (Amresco) was injected into the lateral ventricle of the embryonic brains, which were then subjected to electroporation consisting of five square wave pulses with an amplitude of $35 \mathrm{v}$ (for mice) or $55 \mathrm{v}$ (for rats), a duration of $100 \mathrm{~ms}$, an interval of 1s (ECM830; BTX).

\section{Stripe coating assay}

Poly-dimethylsiloxane (PDMS) molds were fabricated as described previously [71], with a patterned parallel stripes of 80 $\mu \mathrm{m}$ width separated by $120 \mu \mathrm{m}$ gaps. Briefly, PDMS molds were inversely pressed onto poly-D-lysine-coated glass coverslips, and microchannels formed between the PDMS molds and coverslips were used for microfluidic patterning of individual substrates $(0.1$ $\mathrm{mg} / \mathrm{ml}$ collagen, fibronectin or $0.05 \mathrm{mg} / \mathrm{ml}$ laminin, mixed with 5 $\mu \mathrm{g} / \mathrm{ml}$ of fluorescence-conjugated BSA, respectively), which were driven through the microchannels by a vacuum. Substrate solutions were incubated in the microchannels overnight, and PDMS molds were removed, leaving the adsorbed substrates stripes on the glass microscope slides for cell plating.

\section{Diffusive printing assay}

Diffusive printing assay was performed to generate bound substrate gradient as described previously [34] with some modifications. Briefly, silicon molds with parallel grooves, each $350 \mu \mathrm{m}$ in width, $100 \mu \mathrm{m}$ in depth, and $4 \mathrm{~mm}$ apart, were designed and produced by using standard photolithography. Afterwards, liquid PDMS was poured onto the silicon molds, resulting in the formation of PDMS molds with paralleled ridges, which were then vapor-coated to make the surface hydrophobic. Next, certain amount of autoclaved 5\% agarose dissolved in PBS was poured onto sterilized PDMS molds, and solidified agarose gel was detached and cut into $18 \times 18 \mathrm{~mm}$ stamps, with each containing four channels at the bottom. The agarose stamps were then placed on top of epoxy coverslips (Arrayit SuperEpoxy $2.5 \times 10^{12}$ reactive group $/ \mathrm{mm}^{2}$ ) coated with $0.1 \mathrm{mg} / \mathrm{ml} \mathrm{PDL}$, and the laminin substrate solutions $(0.05$ $\mathrm{mg} / \mathrm{ml}$ ) were added into the microchannels between the agarose stamps and the coverslips to make diffusive gradient perpendicular to the channels. After 20 min diffusion, the agarose stamps were removed, and coverslips were air-dried at room temperature for about 30 min until being rinsed with PBS. These coverslips with bound substrate gradients were ready for cell plating.

\section{Brain slice overlay assay}

Brain slice overlay assay was performed by following the methods described previously [72, 73]. Briefly, coronal sections $(300 \mu \mathrm{m})$ of neonatal rat cerebral cortex were cultured on the culture plate inserts (Millipore), in MEM culture medium with Glutamax-1, containing 23\% EBSS, $6.5 \mathrm{mg} / \mathrm{ml}$ D-glucose, $0.06 \%$ Nystatin, 25\% horse serum, and 1\% penicillin-streptomycin. After transfection, dissociated hippocampal neurons from E18.5 rats were plated onto cortical slices, and cultured for 2-3 days before morphology analysis.

\section{Polystyrene beads embedding in brain slice culture}

Laminin (Sigma) or normal mouse IgG (Millipore) proteins were covalently coupled to polystyrene beads (Polybead ${ }^{\circledR}$ Blue Dyed Microspheres, $6.0 \mu \mathrm{m}$, Polysciences) using Glutaraldehyde Kit (Polysciences). The Helios Gene Gun (Bio-Rad) was used to transport coated polystyrene beads into mouse brain slices $(50$ $\mu \mathrm{m})$, with $100-120$ psi pressure and 20-30 mm distance between the gun barrel and the targets. After beads embedding, the brain slices were cultured on sterilized culture plate inserts (Millipore) for 2-3 days before morphology analysis.

\section{Live cell imaging}

Dissociated neurons were transfected with EGFP-EB3 together with individual siRNA construct, and plated on coverslips coated with laminin stripes. At DIV2 or DIV3, immediately before image capture, neurons were switched to the medium for live imaging (20 mM HEPES, pH 7.4, $150 \mathrm{mM} \mathrm{NaCl}, 1 \mathrm{mM} \mathrm{CaCl}_{2}, 5 \mathrm{mM} \mathrm{KCl}, 1$ $\mathrm{mM} \mathrm{MgCl}$, with $1.9 \mathrm{mg} / \mathrm{ml}$ glucose and $1.9 \mathrm{mg} / \mathrm{ml}$ albumin), and were warmed to $37{ }^{\circ} \mathrm{C}$ in $\mathrm{CO}_{2}$ chamber. Movement of EB3 puncta were observed for $15 \mathrm{~min}$, with pictures taken at intervals of $1 \mathrm{~s}$ using Nikon Ti live-cell imaging microscope with Apo TIRF 100× object lens.

\section{Conditioned knockout mice}

The Floxed/Cre approach was used to generate Itgbl conditioned knockout (CKO) mice. The B6; 129-Itgb1tm1Efu/J mice, which possess loxP sites on either side of exon 3 of the Itgbl gene, were crossed with B6.129S2-Emx Itm l(cre) Krj/J mice, which expresses Cre recombinase from the endogenous Emxl locus, resulting in the generation of Itgb1 CKO mice. Emx1-mediated recombination was supposed to occur in approximately $88 \%$ of the neurons in neocortex and hippocampus, and in the glial cells of the pallium, based on the expression pattern of endogenous Emx 1 gene [38]. All animal usage followed guidelines by the Institutional Animal Care and Use Committee of Institute of Neuroscience, Chinese Academy of Sciences.

\section{Acknowledgments}

We thank Dr MM Poo (Institute of Neuroscience, SIBS, CAS) for suggestions on this work and critical reading of the manuscript. This work was supported by the National Basic Research Program (2011CBA00403 to ZGL), and the National Natural Science Foundation of China (31021063 and 30825013 to ZGL, 21025520 to $\mathrm{XYJ}$ ). We also thank Dr JF Chen (Institute of Biochemistry and Cell Biology, SIBS, CAS) for providing reagents and Dr Q Hu of 
ION Imaging Facility with microscope analysis.

\section{References}

1 Arimura N, Kaibuchi K. Neuronal polarity: from extracellular signals to intracellular mechanisms. Nat Rev Neurosci 2007; 8:194-205.

2 Barnes AP, Polleux F. Establishment of axon-dendrite polarity in developing neurons. Annu Rev Neurosci 2009; 32:347-381.

3 Witte H, Neukirchen D, Bradke F. Microtubule stabilization specifies initial neuronal polarization. J Cell Biol 2008; 180:619-632.

4 Bradke F, Dotti CG. The role of local actin instability in axon formation. Science 1999; 283:1931-1934.

5 Schwamborn JC, Püschel AW. The sequential activity of the GTPases Rap1B and Cdc42 determines neuronal polarity. Nat Neurosci 2004; 7:923-929.

6 Hirai S, Banba Y, Satake T, Ohno S. Axon formation in neocortical neurons depends on stage-specific regulation of microtubule stability by the dual leucine zipper kinase-c-jun n-terminal kinase pathway. J Neurosci 2011; 31:6468-6480.

7 Sengottuvel V, Leibinger M, Pfreimer M, Andreadaki A, Fischer D. Taxol facilitates axon regeneration in the mature CNS. J Neurosci 2011; 31:2688-2699.

8 Barnes AP, Solecki D, Polleux F. New insights into the molecular mechanisms specifying neuronal polarity in vivo. Curr Opin Neurobiol 2008; 18:44-52.

9 Bradke F, Dotti CG. Establishment of neuronal polarity: lessons from cultured hippocampal neurons. Curr Opin Neurobiol 2000; 10:574-581.

10 Craig AM, Banker G. Neuronal polarity. Annu Rev Neurosci 1994; 17:267-310.

11 Dotti CG, Sullivan CA, Banker GA. The establishment of polarity by hippocampal neurons in culture. J Neurosci 1988; 8:1454-1468.

12 Barnes AP, Lilley BN, Pan YA, et al. LKB1 and SAD kinases define a pathway required for the polarization of cortical neurons. Cell 2007; 129:549-563.

13 Kishi M, Pan YA, Crump JG, Sanes JR. Mammalian SAD kinases are required for neuronal polarization. Science 2005; 307:929-932.

14 Shelly M, Cancedda L, Heilshorn S, Sumbre G, Poo MM. LKB1/STRAD promotes axon initiation during neuronal polarization. Cell 2007; 129:565-577.

15 Yi JJ, Barnes AP, Hand R, Polleux F, Ehlers MD. TGF-beta signaling specifies axons during brain development. Cell 2010; 142:144-157.

16 Randlett O, Poggi L, Zolessi FR, Harris WA. The oriented emergence of axons from retinal ganglion cells is directed by laminin contact in vivo. Neuron 2011; 70:266-280.

17 Dertinger SK, Jiang X, Li Z, Murthy VN, Whitesides GM. Gradients of substrate-bound laminin orient axonal specification of neurons. Proc Natl Acad Sci USA 2002; 99:12542-12547.

18 Esch T, Lemmon V, Banker G. Local presentation of substrate molecules directs axon specification by cultured hippocampal neurons. J Neurosci 1999; 19:6417-6426.

19 Lathia JD, Patton B, Eckley DM, et al. Patterns of laminins and integrins in the embryonic ventricular zone of the CNS. $J$
Comp Neurol 2007; 505:630-643.

20 Gupton SL, Gertler FB. Integrin signaling switches the cytoskeletal and exocytic machinery that drives neuritogenesis. Dev Cell 2010; 18:725-736.

21 Tan CL, Kwok JC, Patani R, Ffrench-Constant C, Chandran $\mathrm{S}$, Fawcett JW. Integrin activation promotes axon growth on inhibitory chondroitin sulfate proteoglycans by enhancing integrin signaling. J Neurosci 2011; 31:6289-6295.

22 Robles E, Gomez TM. Focal adhesion kinase signaling at sites of integrin-mediated adhesion controls axon pathfinding. Nat Neurosci 2006; 9:1274-1283.

23 Graus-Porta D, Blaess S, Senften M, et al. Beta1-class integrins regulate the development of laminae and folia in the cerebral and cerebellar cortex. Neuron 2001; 31:367-379.

24 Belvindrah R, Graus-Porta D, Goebbels S, Nave KA, Müller U. Beta1 integrins in radial glia but not in migrating neurons are essential for the formation of cell layers in the cerebral cortex. J Neurosci 2007; 27:13854-13865.

25 Belvindrah R, Hankel S, Walker J, Patton BL, Müller U. Betal integrins control the formation of cell chains in the adult rostral migratory stream. J Neurosci 2007; 27:27042717.

26 Huang Z, Shimazu K, Woo NH, et al. Distinct roles of the beta1-class integrins at the developing and the mature hippocampal excitatory synapse. J Neurosci 2006; 26:1120811219.

27 Luque A, Gómez M, Puzon W, Takada Y, Sánchez-Madrid F, Carlos Cabañas. Activated conformations of very late activation integrins detected by a group of antibodies (HUTS) specific for a novel regulatory region $(355-425)$ of the common beta 1 chain. J Biol Chem 1996; 271:11067-11075.

28 Adams JC, Watt FM. Changes in keratinocyte adhesion during terminal differentiation: reduction in fibronectin binding precedes alpha 5 beta 1 integrin loss from the cell surface. Cell 1990; 63:425-435.

29 Carroll JM, Romero MR, Watt FM. Suprabasal integrin expression in the epidermis of transgenic mice results in developmental defects and a phenotype resembling psoriasis. Cell 1995; 83:957-968.

30 Noto K, Kato K, Okumura K, Yagita H. Identification and functional characterization of mouse CD29 with a mAb. Int Immunol 1995; 7:835-842.

31 Bazzoni G, Shih DT, Buck CA, Hemler ME. Monoclonal antibody 9EG7 defines a novel beta 1 integrin epitope induced by soluble ligand and manganese, but inhibited by calcium. $J$ Biol Chem 1995; 270:25570-25577.

32 Polleux F, Giger RJ, Ginty DD, Kolodkin AL, Ghosh A. Patterning of cortical efferent projections by semaphorinneuropilin interactions. Science 1998; 282:1904-1906.

33 Jiang X, Xu Q, Dertinger SK, Stroock AD, Fu TM, Whitesides GM. A general method for patterning gradients of biomolecules on surfaces using microfluidic networks. Anal Chem 2005; 77:2338-2347.

34 Mai J, Fok L, Gao H, Zhang X, Poo MM. Axon initiation and growth cone turning on bound protein gradients. $J$ Neurosci 2009; 29:7450-7458.

35 Almeida EA, Huovila AP, Sutherland AE, et al. Mouse egg integrin alpha 6 beta 1 functions as a sperm receptor. Cell 1995; 81:1095-1104. 
36 Fässler R, Meyer M. Consequences of lack of beta 1 integrin gene expression in mice. Genes Dev 1995; 9:1896-1908.

37 Raghavan S, Bauer C, Mundschau G, Li Q, Fuchs E. Conditional ablation of betal integrin in skin. Severe defects in epidermal proliferation, basement membrane formation, and hair follicle invagination. J Cell Biol 2000; 150:11491160.

38 Gorski JA, Talley T, Qiu M, Puelles L, Rubenstein JL, Jones KR. Cortical excitatory neurons and glia, but not GABAergic neurons, are produced in the Emx1-expressing lineage. $J \mathrm{Neu}$ rosci 2002; 22:6309-6314.

39 Molnar Z, Adams R, Blakemore C. Mechanisms underlying the early establishment of thalamocortical connections in the rat. J Neurosci 1998; 18:5723-5745.

40 Kawano H, Fukuda T, Kubo K, et al. Pax-6 is required for thalamocortical pathway formation in fetal rats. J Comp Neurol 1999; 408:147-160.

41 Fujimori KE, Takeuchi K, Yazaki T, Uyemura K, Nojyo Y, Tamamki N. Expression of L1 and TAG-1 in the corticospinal, callosal, and hippocampal commissural neurons in the developing rat telencephalon as revealed by retrograde and in situ hybridization double labeling. J Comp Neurol 2000; 417:275-288.

42 Denaxa M, Chan CH, Schachner M, Parnavelas JG, Karagogeos D. The adhesion molecule TAG-1 mediates the migration of cortical interneurons from the ganglionic eminence along the corticofugal fiber system. Development 2001; 128:4635-4644.

43 Espinosa A, Gil-Sanz C, Yanagawa Y, Fairén A. Two separate subtypes of early non-subplate projection neurons in the developing cerebral cortex of rodents. Front Neuroanat 2009; 3:27.

44 Felsenfeld DP, Hynes MA, Skoler KM, Furley AJ, Jessell TM. TAG-1 can mediate homophilic binding, but neurite outgrowth on TAG-1 requires an L1-like molecule and beta 1 integrins. Neuron 1994; 12:675-690.

45 Förster E, Tielsch A, Saum B, et al. Reelin, Disabled 1, and beta 1 integrins are required for the formation of the radial glial scaffold in the hippocampus. Proc Natl Acad Sci USA 2002; 99:13178-13183.

46 Radakovits R, Barros CS, Belvindrah R, Patton B, Müller U. Regulation of radial glial survival by signals from the meninges. J Neurosci 2009; 29:7694-7705.

47 Saito T, Nakatsuji N. Efficient gene transfer into the embryonic mouse brain using in vivo electroporation. Dev Biol 2001; 240:237-246.

48 Loulier K, Lathia JD, Marthiens V, et al. beta1 integrin maintains integrity of the embryonic neocortical stem cell niche. PLoS Biol 2009; 7:e1000176.

49 Guo W, Jiang H, Gray V, Dedhar S, Rao Y. Role of the integrin-linked kinase (ILK) in determining neuronal polarity. Dev Biol 2007; 306:457-468.

50 Delcommenne M, Tan C, Gray V, Rue L, Woodgett J, Dedhar S. Phosphoinositide-3-OH kinase-dependent regulation of glycogen synthase kinase 3 and protein kinase B/AKT by the integrin-linked kinase. Proc Natl Acad Sci USA 1998; 95:11211-11216.

51 Westermann S, Weber K. Post-translational modifications regulate microtubule function. Nat Rev Mol Cell Biol 2003; 4:938-947.
52 Stepanova T, Slemmer J, Hoogenraad CC, et al. Visualization of microtubule growth in cultured neurons via the use of EB3-GFP (end-binding protein 3-green fluorescent protein). $J$ Neurosci 2003; 23:2655-2664.

53 Cappello S, Attardo A, Wu X, et al. The Rho-GTPase cdc42 regulates neural progenitor fate at the apical surface. Nat Neurosci 2006; 9:1099-1107.

54 Chen YM, Wang QJ, Hu HS, et al. Microtubule affinityregulating kinase 2 functions downstream of the PAR-3/ PAR-6/atypical PKC complex in regulating hippocampal neuronal polarity. Proc Natl Acad Sci USA 2006; 103:85348539.

55 Costa MR, Wen G, Lepier A, Schroeder T, Götz M. Parcomplex proteins promote proliferative progenitor divisions in the developing mouse cerebral cortex. Development 2008; 135:11-22.

56 Shi SH, Jan LY, Jan YN. Hippocampal neuronal polarity specified by spatially localized mPar3/mPar6 and PI3-kinase activity. Cell 2003; 112:63-75.

57 Zhang X, Zhu J, Yang GY, et al. Dishevelled promotes axon differentiation by regulating atypical protein kinase C. Nat Cell Biol 2007; 9:743-754.

58 Palazzo AF, Eng CH, Schlaepfer DD, Marcantonio EE, Gundersen GG. Localized stabilization of microtubules by integrin- and FAK-facilitated Rho signaling. Science 2004; 303:836-839.

59 Lim CJ, Han J, Yousefi N, et al. Alpha4 integrins are type I cAMP-dependent protein kinase-anchoring proteins. Nat Cell Biol 2007; 9:415-421.

60 Toyoshima F, Nishida E. Integrin-mediated adhesion orients the spindle parallel to the substratum in an EB1- and myosin X-dependent manner. EMBO J 2007; 26:1487-1498.

61 Reverte CG, Benware A, Jones CW, LaFlamme SE. Perturbing integrin function inhibits microtubule growth from centrosomes, spindle assembly, and cytokinesis. J Cell Biol 2006; 174:491-497.

62 Adler CE, Fetter RD, Bargmann CI. UNC-6/Netrin induces neuronal asymmetry and defines the site of axon formation. Nat Neurosci 2006; 9:511-518.

63 Lerman O, Ben-Zvi A, Yagil Z, Behar O. Semaphorin3A accelerates neuronal polarity in vitro and in its absence the orientation of DRG neuronal polarity in vivo is distorted. $\mathrm{Mol}$ Cell Neurosci 2007; 36:222-234.

64 Staquicini FI, Dias-Neto E, Li J, et al. Discovery of a functional protein complex of netrin-4, laminin gammal chain, and integrin alpha6beta1 in mouse neural stem cells. Proc Natl Acad Sci USA 2009; 106:2903-2908.

65 Hagedorn EJ, Yashiro H, Ziel JW, Ihara S, Wang Z, Sherwood DR. Integrin acts upstream of netrin signaling to regulate formation of the anchor cell's invasive membrane in C. elegans. Dev Cell 2009; 17:187-198.

66 Stanco A, Szekeres C, Patel N, et al. Netrin-1-alpha3beta1 integrin interactions regulate the migration of interneurons through the cortical marginal zone. Proc Natl Acad Sci USA 2009; 106:7595-7600.

67 Yebra M, Montgomery AM, Diaferia GR, et al. Recognition of the neural chemoattractant Netrin-1 by integrins alpha6beta4 and alpha3beta1 regulates epithelial cell adhesion and migration. Dev Cell 2003; 5:695-707. 
68 Höpker VH, Shewan D, Tessier-Lavigne M, Poo M, Holt C. Growth-cone attraction to netrin-1 is converted to repulsion by laminin-1. Nature 1999; 401:69-73.

69 Nakamoto T, Kain KH, Ginsberg MH. Neurobiology: new connections between integrins and axon guidance. Curr Biol 2004; 14:R121-123.

70 Stevens A, Jacobs JR. Integrins regulate responsiveness to slit repellent signals. $J$ Neurosci 2002; 22:4448-4455.

$71 \mathrm{Li} \mathrm{N}, \mathrm{Hsu} \mathrm{CH}$, Folch A. Parallel mixing of photolithographically defined nanoliter volumes using elastomeric microvalve arrays. Electrophoresis 2005; 26:3758-3764.

72 De Simoni A, Yu LM. Preparation of organotypic hippocampal slice cultures: interface method. Nat Protoc 2006; 1:14391445.

73 Polleux F, Ghosh A. The slice overlay assay: a versatile tool to study the influence of extracellular signals on neuronal development. Sci STKE 2002; 2002:p19.

(Supplementary information is linked to the online version of the paper on the Cell Research website.) 